\title{
Genomic analysis of a riboflavin- overproducing Ashbya gossypii mutant isolated by disparity mutagenesis
}

Tatsuya Kato ${ }^{1,2}$, Junya Azegami ${ }^{2}$, Ami Yokomori ${ }^{2}$, Hideo Dohra ${ }^{3}$, Hesham A. El Enshasy ${ }^{4}$ and Enoch Y. Park ${ }^{1,2^{*}}$ (D)

\begin{abstract}
Background: Ashbya gossypii naturally overproduces riboflavin and has been utilized for industrial riboflavin production. To improve riboflavin production, various approaches have been developed. In this study, to investigate the change in metabolism of a riboflavin-overproducing mutant, namely, the W122032 strain (MT strain) that was isolated by disparity mutagenesis, genomic analysis was carried out.

Results: In the genomic analysis, 33 homozygous and 1377 heterozygous mutations in the coding sequences of the genome of MT strain were detected. Among these heterozygous mutations, the proportion of mutated reads in each gene was different, ranging from 21 to 75\%. These results suggest that the MT strain may contain multiple nuclei containing different mutations. We tried to isolate haploid spores from the MT strain to prove its ploidy, but this strain did not sporulate under the conditions tested. Heterozygous mutations detected in genes which are important for sporulation likely contribute to the sporulation deficiency of the MT strain. Homozygous and heterozygous mutations were found in genes encoding enzymes involved in amino acid metabolism, the TCA cycle, purine and pyrimidine nucleotide metabolism and the DNA mismatch repair system. One homozygous mutation in AgILV2 gene encoding acetohydroxyacid synthase, which is also a flavoprotein in mitochondria, was found. Gene ontology (GO) enrichment analysis showed heterozygous mutations in all 22 DNA helicase genes and genes involved in oxidation-reduction process.

Conclusion: This study suggests that oxidative stress and the aging of cells were involved in the riboflavin overproduction in A. gossypii riboflavin over-producing mutant and provides new insights into riboflavin production in A. gossypii and the usefulness of disparity mutagenesis for the creation of new types of mutants for metabolic engineering.
\end{abstract}

Keywords: Ashbya gossypii, Riboflavin production, Disparity mutagenesis, Homozygous mutation, Heterozygous mutation

\section{Background}

Ashbya gossypii, a filamentous fungus, is a riboflavin producer and has been utilized for industrial riboflavin production. Therefore, many studies on the metabolic mechanism of riboflavin production in A. gossypii have

\footnotetext{
* Correspondence: park.enoch@shizuoka.ac.jp

'Green Chemistry Research Division, Research Institute of Green Science and Technology, Shizuoka University, Ohya 836, Suruga-ku, Shizuoka, Japan ${ }^{2}$ Department of Agriculture, Graduate School of Integrated Science and Technology, Shizuoka University, Ohya 836, Suruga-ku, Shizuoka, Japan Full list of author information is available at the end of the article
}

been carried out, and several overproducing mutants have been isolated [1]. In addition, the genome of $A$. gossypii is very similar to that of Saccharomyces cerevisiae, which is a budding yeast, and $91 \%$ of 4476 annotated $A$. gossypii genes are syntenic to those of S. cerevisiae [2]. This finding provides for many researchers to identify differences between the growth of filamentous fungi and budding yeasts [3].

Isocitrate lyase (ICL), which catalyzes the cleavage reaction of isocitrate to succinate and glyoxylate, is an important enzyme for riboflavin production in A. gossypii

(c) The Author(s). 2020 Open Access This article is licensed under a Creative Commons Attribution 4.0 International License, which permits use, sharing, adaptation, distribution and reproduction in any medium or format, as long as you give appropriate credit to the original author(s) and the source, provide a link to the Creative Commons licence, and indicate if changes were made. The images or other third party material in this article are included in the article's Creative Commons licence, unless indicated otherwise in a credit line to the material. If material is not included in the article's Creative Commons licence and your intended use is not permitted by statutory regulation or exceeds the permitted use, you will need to obtain permission directly from the copyright holder. To view a copy of this licence, visit http://creativecommons.org/licenses/by/4.0/ The Creative Commons Public Domain Dedication waiver (http://creativecommons.org/publicdomain/zero/1.0/) applies to the data made available in this article, unless otherwise stated in a credit line to the data. 
[4]. The mutant isolated using itaconate, which is an ICL inhibitor, produced a 25-fold higher level of riboflavin in soybean oil-containing medium than the wild type. The mutant isolated on oxalate-containing medium showed a 5 -fold higher riboflavin yield than wild type in rapeseed oil medium [5]. In addition, genetic engineering of this fungus has been utilized for riboflavin production [6]. Overexpression of riboflavin biosynthetic genes in $A$. gossypii contributed to the enhancement of riboflavin production [7]. Disruption of cytoplasmic serine hydroxymethyltransferase gene (AgSHM2) in A. gossypii also improved riboflavin production 10-fold compared to the wild type [8]. Reinforcement of the purine biosynthetic pathway in A. gossypii also improved riboflavin production $[9,10]$. These results show that glycine and the purine biosynthetic pathway are important factors for riboflavin production in A. gossypii. Along with genetic engineering, metabolic investigation using a ${ }^{13} \mathrm{C}$ tracer has been carried out to improve riboflavin production in A. gossypii [11, 12].

Recently, the A. gossypii w122032 mutant (MT strain), which is an overproducer of riboflavin, was isolated by the disparity mutagenesis method [13]. This disparity mutagenesis was first demonstrated by Furusawa et al., and disparity theory has been developed by computer simulation [14, 15]. Expression of error-prone DNA polymerase $\delta$ in hosts generates increased diversity of hosts that have mutated genomes and leads to the isolation of mutant strains with desired properties. In the MT strain, mutation sites in metabolic pathways were suggested by DNA microarray analysis, proteome analysis and metabolic flux analysis $[13,16]$. However, definite mutation sites have not been identified to date.

In this study, using a next-generation DNA sequencer, genome analysis of the MT strain was carried out, and mutation sites in the genome of this mutant compared to that of wild type were determined to clarify the mechanism of the riboflavin over-production in MT strain considering the previous analyses of MT strain $[13,16]$. In addition, we discussed the roles of genes mutated in the MT strain.

\section{Results and discussion}

Genome analysis of each strain and identification of mutations in the genome sequence of MT

We previously reported that the riboflavin overproducing mutant (MT strain) was isolated by disparity mutagenesis in the presence of $\mathrm{H}_{2} \mathrm{O}_{2}$, itaconate and oxalate and phenotypes of this MT strain were characterized by transcriptomic, proteomic and metabolic flux analyses $[13,16]$. In this study, to reveal the genotype of MT strain, genome resequencing and single-nucleotide polymorphisms (SNP) analysis were carried out. Wholegenome shotgun sequencing for WT and MT generated $1,083,909$ and $1,519,777$ high-quality read pairs totaling approximately 593 and $836 \mathrm{Mb}$, respectively. The highquality reads of WT and MT were aligned to the reference genome of A. gossypii ATCC10895, resulting in sequence coverages of 41.9-43.4 and 46.7-53.6, respectively, for chromosome I-VII. Among the variants identified by the Genome Analysis Toolkit (GATK) based on the aligned reads for WT and MT, mutations in open reading frames (ORFs), missense mutations, frameshift mutations and nonsense mutations were analyzed. In WT, which is same as the original strain A. gossypii ATCC10895, amino acid sequences encoded by all ORFs were the same as those of strain ATCC10895, except for the SEN2 gene (AGOS_ AGR073C), which encodes a subunit of the tRNA splicing endonuclease in S. cerevisiae (Supplementary material Table S1). This result indicates that this WT, which has been maintained in our laboratory, could have gained this heterozygous mutation. However, this WT was used in this study because this gene may not be involved in riboflavin production, given the function of the gene product. Additionally, some silent mutations were also detected (data not shown).

From the single-nucleotide variant (SNV) analysis between the genome sequences of WT and MT, we detected 33 homozygous and 1377 heterozygous mutations in the coding sequences of the genome of MT strain (Supplementary materials Tables S1 and S2), which cause missense, nonsense and frameshift mutations, in addition to silent mutations. These heterozygous mutations suggest that nuclei of the MT strain are polyploid. In the 1377 heterozygous mutations, the proportion of mutations in each gene was different. The highest proportion was 75\% (chromosome VI:799,900 in AgOCT1, AGOS_AFR198W), and the lowest proportion was 21\% (chromosome VII:198,537 and 198541 in AgATP1, AGOS_AGL272C) (Fig. 1). Most heterozygous mutants were found to have ratios of $40-60 \%$. These results suggest that the MT strain may contain multiple nuclei containing different mutations. To prove its ploidy, we tried to isolate haploid spores from the MT strain, but this strain did not produce spores under the conditions tested. This result indicates that the MT strain lost the ability to sporulate even though it was previously reported that the riboflavin production in A. gossypii is related with its spore production [17]. A. gossypii is a naturally multinucleate fungus, but this fungus may be haploid, and the spores of this fungus produced by asexual sporulation are also haploid $[2,18]$. However, Anderson et al. reported that ploidy variation was observed in A. gossypii with minor aneuploidy [19]. In this study, the proportion of heterozygous mutations in each gene ranged from 75 to $21 \%$, and most heterozygous mutations were found at $40-60 \%$. This result may be caused by the polyploidy or multinucleate cells of this organism. Anderson et al. [19] also discussed the low germination 


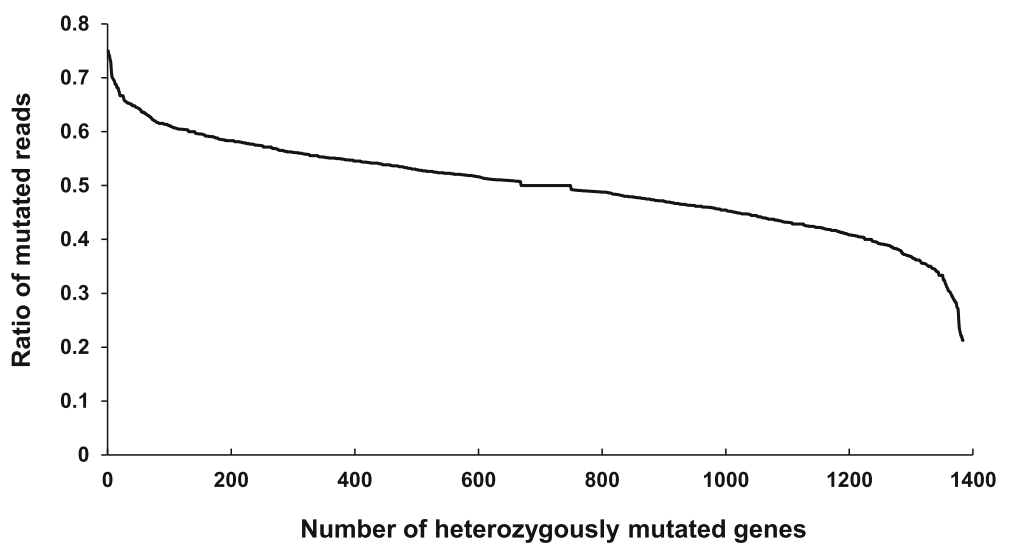

Fig. 1 Proportion of mutated reads in each gene among 1377 heterozygous mutations in the coding sequences of the MT genome. The highest proportion was 75\% (OCT1, AGOS_AFR198W), and the lowest proportion was 21\% (AGOS_AGL272C). Most heterozygous mutations were detected at $40-60 \%$

frequency of spores produced from variable polypoid nuclei. Two possibilities were suggested: a reduction in ploidy to uninucleate haploid spores and the formation of spores with variable ploidy. In this study, the MT strain never produced haploid spores.

Which corresponds, interestingly, we found a region representing $\sim 2$-fold sequence coverage compared to other regions in chromosome VII of the MT strain, which correspond to the rRNA gene repeats (Chr VII:441,317762,344) (Fig. 2). In yeasts, the number of rRNA gene repeats is normally maintained for genome stability and determination of life span [20, 21]. Moreover, the rRNA gene controls chromosome homeostasis [22]. When the number of rRNA gene repeats increases, rRNA gene instability and aging phenotypes are observed. Silva et al. showed that the riboflavin-overproducing Ashbya mutants are vulnerable to photoinduced oxidative DNA damage and accumulate reactive oxygen species (ROS) [23]. The ROS is largely involved in the aging of cells, suggesting that the riboflavin production in A. gossypii may be associated with the aging of cells.

It is reasonable that homozygous mutations have more crucial effects on riboflavin production in the MT strain compared to heterozygous mutations. We selected candidate mutations among 33 homozygous mutations in the coding sequence of the genome of MT strain, as shown in Table 1. Among the 33 homozygous mutations, the SEN2 gene (AGOS_AGR073C) has one homozygous mutation in the MT strain, in contrast to the WT strain used in this study, which has one heterozygous mutation at the same nucleotide. Four homozygous mutations in the amino acid metabolism of $A$. gossypii were detected.

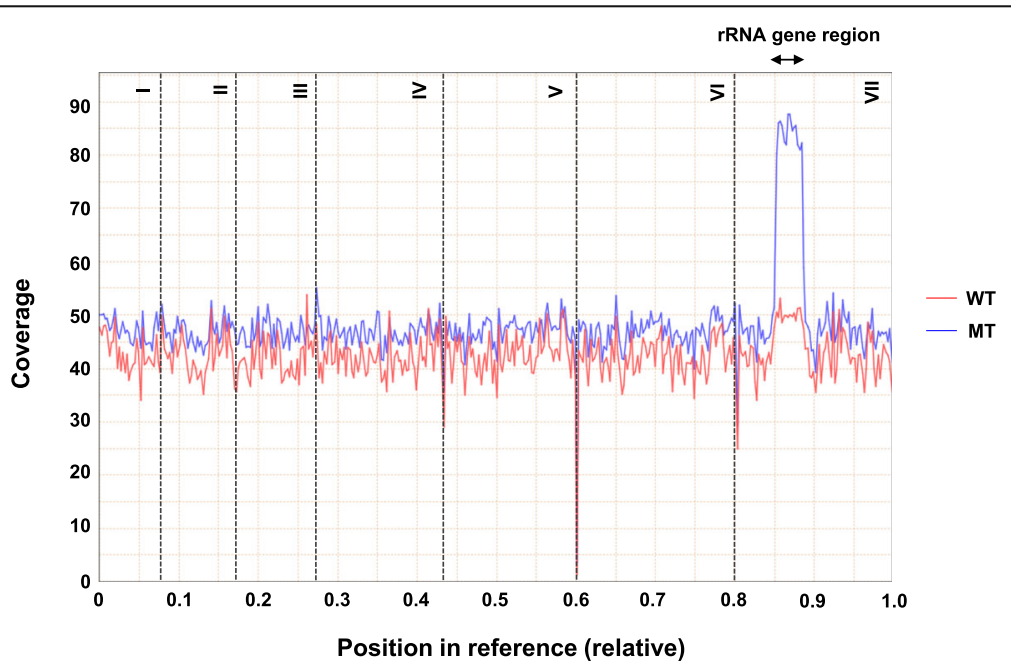

Fig. 2 Sequence coverage line graph of chromosomes in MT strain and WT strain. Compared to the WT strain, a large number of rRNA gene repeat sequences in chromosome VII were detected in the MT strain 
Table 1 Homozygous mutations of genes in MT strain

\begin{tabular}{|c|c|c|c|c|c|c|c|c|c|c|c|}
\hline \multirow[t]{2}{*}{ Chromosome } & \multirow[t]{2}{*}{ Position } & \multirow{2}{*}{$\begin{array}{l}\text { WT } \\
\text { seq. }\end{array}$} & \multirow{2}{*}{$\begin{array}{l}\text { MT } \\
\text { seq. }\end{array}$} & \multirow{2}{*}{ Quality } & \multirow[t]{2}{*}{ Mutation } & \multirow[t]{2}{*}{ Gene } & \multirow[t]{2}{*}{ Product } & \multirow{2}{*}{$\begin{array}{l}\text { DNA } \\
\text { changes }\end{array}$} & \multirow{2}{*}{$\begin{array}{l}\text { Protein } \\
\text { changes }\end{array}$} & \multicolumn{2}{|c|}{ Number } \\
\hline & & & & & & & & & & $\begin{array}{l}\overline{W T} \\
\text { seq. }\end{array}$ & $\begin{array}{l}\text { MT } \\
\text { seq. }\end{array}$ \\
\hline$\|$ & 496,139 & C & $\mathrm{T}$ & 1495.42 & missense & AGOS_ABR055C & $\begin{array}{l}\text { Transcriptional activator } \\
\text { (AgSOK2 or AgPHD1) }\end{array}$ & $\begin{array}{l}\text { C.1180G > } \\
\text { A }\end{array}$ & G394R & 0 & 38 \\
\hline III & 726,948 & CG & C & 1167.38 & frameshift & AGOS_ACR215C & $\begin{array}{l}\text { Cytosolic serine } \\
\text { hydroxymethyltransferase } \\
\text { (AgSHM2) }\end{array}$ & c.1332delC & p.Q445fs & 0 & 30 \\
\hline IV & $\begin{array}{l}1,433 \\
004\end{array}$ & $\mathrm{~T}$ & A & 1442.42 & missense & AGOS_ADR404C & $\begin{array}{l}\text { Oleate-activated transcription } \\
\text { factor (AgOAF1 or AgPIP2) }\end{array}$ & c. $2317 \mathrm{~A}>\mathrm{T}$ & p.T773S & 0 & 38 \\
\hline IV & $\begin{array}{l}1,433 \\
040\end{array}$ & $\mathrm{~T}$ & G & 1455.42 & missense & AGOS_ADR404C & $\begin{array}{l}\text { Oleate-activated transcription } \\
\text { factor (AgOAF1 or AgPIP2) }\end{array}$ & $\begin{array}{l}\text { C. } 2281 \mathrm{~A}> \\
\mathrm{C}\end{array}$ & p.T761P & 0 & 39 \\
\hline IV & 199,365 & G & A & 1523.42 & missense & AGOS_ADL287C & Chorismate synthase $(\mathrm{AgARO})^{\mathrm{a}}$ & c. $206 C>T$ & p.T69M & 0 & 39 \\
\hline V & 70,024 & C & A & 1836.42 & missense & AGOS_AEL305C & $\begin{array}{l}\text { Large subunit of } \\
\text { acetohydroxyacid synthase } \\
\text { (AglLV2) }^{\mathrm{a}}\end{array}$ & c. $1365 G>T$ & p.Q455H & 0 & 46 \\
\hline VII & 791,717 & C & A & 1505.42 & missense & $\begin{array}{l}\text { AGOS } \\
\text { AGL123W }\end{array}$ & Cytidine deaminase (AgCDD1) & c. $314 C>A$ & p.P105Q & 0 & 41 \\
\hline VII & 962,069 & G & A & 1560.42 & nonsense & AGOS_AGL036C & Heat shock protein 104 (AgHSP104) & c. $1066 C>T$ & p.Q356* & 0 & 42 \\
\hline $\mathrm{VI}$ & $\begin{array}{l}1,753 \\
850\end{array}$ & G & A & 1884.42 & missense & $\begin{array}{l}\text { AGOS } \\
\text { AGR382W }\end{array}$ & $\begin{array}{l}\text { L-aminoadipate-semialdehyde } \\
\text { dehydrogenase-phosphopantetheinyl } \\
\text { transferase (AgLYS5) }\end{array}$ & c.365G > A & p.R122H & 0 & 49 \\
\hline
\end{tabular}

These homozygous mutations are a subset among all 32 homozygous mutations which are shown in Table S1

a Flavoproteins

*Translation stops here

First, a frameshift mutation in the AgSHM2 gene (AGOS_ACR215C) was detected in the genome of the MT strain. This gene encodes serine hydroxymethyltransferase 2 (SHMT), and it was previously reported that disruption of this gene enhanced the productivity of riboflavin in A. gossypii, although the growth of the organism was compromised [7]. The frameshift mutation causes the deletion of 25 amino acid residues at the Cterminus of AgSHM2 and the addition of 6 extra amino acid residues in the deletion mutant. This $\mathrm{C}$-terminal region may not be directly involved in catalytic activity [24]. However, the L474F mutation in this region of human and rabbit SHMT causes a decrease in the binding of this protein to co-factors [25]. Therefore, this frameshift mutation in the MT strain may lead to a decrease in the SHMT activity of AgSHM2. In addition to the homozygous frameshift mutation, one heterozygous mutation $(593 \mathrm{G} \rightarrow \mathrm{A})$, which causes a missense mutation, R198Q, was also detected in the AgSHM2 gene.

Second, a missense mutation $(206 \mathrm{C} \rightarrow \mathrm{T})$ in the $A g A R O 2$ gene (AGOS_ADL287C), which produces the T69M mutant, was detected. In S. cerevisiae, this gene encodes chorismate synthase, which produces chorismate, a building block of aromatic compounds. Because T69 in the chorismate synthase of $S$. cerevisiae is distant from the catalytic site, this residue may not be directly involved in catalytic activity [26]. In addition, this enzyme also exhibits flavin reductase activity for the synthesis of reduced flavin mononucleotide (FMN), which is required for chorismate synthase activity.
Third, a missense mutation $(1365 \mathrm{G} \rightarrow \mathrm{T})$ in the AgILV2 gene (AGOS_AEL305C), which produces the Q455H mutant, was detected. In S. cerevisiae, this gene encodes the large subunit of acetohydroxyacid synthase (AHAS), which solely catalyzes the synthesis of 2-acetolactate and 2-aceto-2-hydroxybutyrate. This reaction is the first step of branched-chain amino acid biosynthesis. This mutation may not have considerable effects on enzymatic activity because Q455 is not in the co-factor-binding sites [27]. This enzyme requires flavin adenine dinucleotide (FAD) as a co-factor, even though this reaction does not require oxidation and reduction. A small subunit of AHAS encoded by the ScILV6 gene regulates the AHAS activity of ScILV2 in yeast [28]. A. gossypii also has AgILV2 and AgILV6 genes. In AgILV6 genes, three heterozygous missense mutations $(140 \mathrm{G} \rightarrow \mathrm{A}, \mathrm{S} 47 \mathrm{~N} ; 155 \mathrm{G} \rightarrow \mathrm{A}, \mathrm{S} 52 \mathrm{~N}$; $673 \mathrm{G} \rightarrow \mathrm{T}, \mathrm{G} 225 \mathrm{C}$ ) were detected.

Fourth, a missense mutation $(365 \mathrm{G} \rightarrow \mathrm{A})$ in the AgLYS5 gene (AGOS_AGR382W), which produces the R122H mutant, was detected. In S. cerevisiae, ScLYS5 (4'-phosphopantetheinyl transferase, PPTase) converts the apo-form of ScLYS2 ( $\alpha$-aminoadipate reductase) to the active holo-form by the transfer of phosphopantetheine and is present in the lysine biosynthetic pathway [29]. In addition to modification, PPTase is involved in fungal growth, the biosynthesis of secondary metabolites and asexual and sexual development [30, 31].

In pyrimidine metabolism in A. gossypii, one homozygous mutation was detected in the $A g C D D 1$ gene 
(AGOS_AGL123W), which encodes cytosine deaminase in $S$. cerevisiae. This enzyme catalyzes the conversion of cytidine to uridine in the pyrimidine salvage pathway in S. cerevisiae [32]. In A. gossypii, in the pyrimidine salvage pathway, uracil phosphoribosyltransfrase, encoded by the AgFUR1 gene, controls the amount of phosphoribosyl pyrophosphate (PRPP), which is one of the precursors of riboflavin in this organism [33].

Regarding the riboflavin production in A. gossypii, one missense homozygous mutation $(1180 \mathrm{G} \rightarrow \mathrm{A})$ was detected in AgSOK2 gene (AGOS_ABR055C) of MT strain. $\mathrm{AgSOK} 2$ is one of fungal-specific group of transcription factors and involved in the sporulation and riboflavin production in A. gossypii [34]. Deletion of AgSOK2 gene led to the strong reduction of the riboflavin production and the deficiency of the sporulation by the downregulation of $A g I M E 2$ and $A g N D T 80$ gene. In MT strain, the riboflavin overproduction and the sporulation deficiency were observed even though AgSOK2 gene had one homozygous mutation. Therefore, it is possible that the riboflavin production and the sporulation in A. gossypii may be regulated differently by AgSOK2 or the homozygous mutation in $\mathrm{AgSOK} 2$ gene may cause the sporulation deficiency but may not cause the reduction of riboflavin production.

Two homozygous mutation $(2317 \mathrm{~A} \rightarrow \mathrm{T}$ and $2281 \mathrm{~A} \rightarrow$ C) in AgOAF1 gene (AGOS_ADR404C) were also found in the genome of MT strain. In the conventional medium previously reported (initial rapeseed oil concentration 100 g/L) [13], WT and MT strains consumed 78.6 and $62.7 \mathrm{~g} /$ $\mathrm{L}$ of rapeseed oil for 144 and $168 \mathrm{~h}$ cultivation in a $3 \mathrm{~L}$ jarfermentor, respectively (unpublished data). Riboflavin production in WT and MT strains during the cultivation was 1.52 and $6.49 \mathrm{~g} / \mathrm{L}$, respectively. This result corresponded to the data in this study showing two homozygous mutations in AgOAF1 gene (AGOS_ADR404C) encoding a subunit of an oleate-activated transcription factor which binds to the oleate response element in promoters of oleate-responsive genes. A. gossypii has more two genes encoding homologs of ScOAF1 gene (AGOS_ADR403C and AGOS_ADR405C). AGOS_ADR403C and AGOS ADR405C also had one and two heterozygous mutations, respectively (Supplementary material Table S2).

In the MT strain, 1377 heterozygous mutations in the coding sequences were also detected (Supplementary material Table S2). Heterozygous mutations usually lead to less critical effects than homozygous mutations $[35,36]$. However, heterozygous mutations sometimes have negative effects on protein functions as well as haploinsufficiency [37, 38]. In addition, some mutated proteins that form multimers exhibit dominant-negative effects on functions [39, 40]. Therefore, it is possible that heterozygous mutations also have some effect on riboflavin production in the MT strain. Among the 1377 heterozygous mutations in the coding sequences, unusual heterozygous mutations were detected (Table 2). Most genes in the TCA cycle have heterozygous mutations. In particular, three genes, namely, AgSDH1 (AGOS_ACR052W), AgSDH2 (AGOS_ACL065C), and $A g S D H 3$ (AGOS_AFR207C), encoding subunits of succinate dehydrogenase in S. cerevisiae, have heterozygous mutations. In addition, several genes encoding flavoproteins in the mitochondria also have heterozygous mutations. $\mathrm{AgSDH} 1$ is also a flavoprotein. Flavoproteins in mitochondria of yeasts function in redox processes via the transfer of electrons [41]. In addition, the flavin in flavoproteins participates in the reduction of heme iron or iron-sulfur clusters. In this study, we detected several homozygous mutations (AgARO2, AgILV2) and heterozygous mutations $\{A g S D H 1$, AgPDX1 (AGOS AGR323C), AgNDI1 (AGOS_AFR447C), AgDLD1 (AGOS_ AER321W), AgCBR1 (AGOS_ADL087W), AgGLR1 (AGOS_AGR196W), AgMTO1 (AGOS_AGR196W), AgMET5 (AGOS_ABL077W), AgPUT1 (AGOS AGL165W), AgFAS1 (AGOS_AER085C), AgHEM14 (AGOS_AAR021W), AgERV2 (AGOS_ACR175W), and AgERO1 (AGOS_ADL348W)\} in genes encoding flavoproteins in S. cerevisiae. It is possible that the riboflavin overproduction in the MT strain is associated with these mutations of genes encoding flavoproteins and dysfunction of the TCA cycle. MT strain is hypothesized to have mitochondrial dysfunction because most genes in the TCA cycle and genes encoding flavoproteins have heterozygous mutations. One homozygous mutation in AgILV2 gene which encodes a flavoprotein, AHAS, localized in mitochondria, was also found (Tables 2 and 3). In humans, riboflavin supplementation rescues the mitochondrial disorders associated with the deficiencies of some flavoproteins and respiratory chains [42]. Additionally, we previously reported that the expression of genes involved in TCA cycles in MT strain was decreased compared to WT strain. Also the MT strain shown the decreased succinate and increased lactate and pyruvate compared to WT strain [13, 16]. These previous results also suggest the overproduction of riboflavin in the MT strain may also be associated with mitochondrial dysfunction.

Related to the heterozygous mutations in flavoprotein genes, a heterozygous mutation in the AgFMN1 gene (AGOS_ABL109W) was detected (Table 2). In S. cerevisiae, this gene encodes riboflavin kinase, which catalyzes the synthesis of FMN from riboflavin. FMN is converted to FAD by FAD synthase. The downregulation of $A g F M N 1$ gene expression prevented riboflavin consumption in this fungus, and the ribC-deleted mutant deregulated riboflavin production in $B$. subtilis by preventing FMN and FAD accumulation [43, 44]. Therefore, this mutation may partially contribute to riboflavin overproduction in the MT strain by partial restriction of the riboflavin flow to FMN. Additionally, heterozygous 
Table 2 Heterozygous mutations in genes involved in metabolisms

\begin{tabular}{|c|c|c|c|c|c|c|c|c|c|c|c|c|}
\hline \multirow[t]{2}{*}{ Chromosome } & \multirow[t]{2}{*}{ Position } & \multirow[t]{2}{*}{$\begin{array}{l}\text { Wt } \\
\text { seq. }\end{array}$} & \multirow[t]{2}{*}{$\begin{array}{l}\text { MT } \\
\text { seq }\end{array}$} & \multirow[t]{2}{*}{ Quality } & \multirow[t]{2}{*}{ Mutation } & \multirow[t]{2}{*}{ Gene } & \multirow[t]{2}{*}{ Product } & \multirow[t]{2}{*}{$\begin{array}{l}\text { DNA } \\
\text { changes }\end{array}$} & \multirow[t]{2}{*}{$\begin{array}{l}\text { Protein } \\
\text { changes }\end{array}$} & \multicolumn{2}{|c|}{$\begin{array}{l}\text { Read } \\
\text { number }\end{array}$} & \multirow{2}{*}{$\begin{array}{l}\text { MT } \\
\text { seq. } \\
\text { Ratio }\end{array}$} \\
\hline & & & & & & & & & & $\begin{array}{l}\text { WT } \\
\text { seq. }\end{array}$ & $\begin{array}{l}\text { MT } \\
\text { seq. }\end{array}$ & \\
\hline \multicolumn{13}{|c|}{ Glycolysis/Gluconeogenesis } \\
\hline III & 456,890 & C & $\mathrm{T}$ & 327.19 & missense & $\begin{array}{l}\text { AGOS } \\
\text { ACR056W }\end{array}$ & Phosphoglycerate mutase (AgGPM1) & c.374C > T & p.A125V & 28 & 12 & 0.300 \\
\hline IV & 287,997 & $\mathrm{~T}$ & C & 503.19 & missense & $\begin{array}{l}\text { AGOS } \\
\text { ADL237C }\end{array}$ & 6-phosphofructo-2-kinase (AgPFK26) & $\begin{array}{l}\text { C.1796A> } \\
G\end{array}$ & p.D599G & 24 & 18 & 0.429 \\
\hline IV & $\begin{array}{l}1,362 \\
124\end{array}$ & A & T & 725.19 & missense & $\begin{array}{l}\text { AGOS }_{\text {ADR368W }} \\
\text { ADR }\end{array}$ & Pyruvate kinase (AgPYK1) & c. $1040 \mathrm{~A}>\mathrm{T}$ & p.K347M & 21 & 23 & 0.523 \\
\hline V & 242,262 & A & C & 708.19 & missense & $\begin{array}{l}\text { AGOS } \\
\text { AEL208W }\end{array}$ & $\begin{array}{l}\text { Alpha subunit of phosphofructokinase } \\
\text { (AgPFK1) }\end{array}$ & c. $2255 \mathrm{~A}>\mathrm{C}$ & p.K752T & 27 & 23 & 0.460 \\
\hline V & 426,255 & C & T & 700.19 & missense & $\begin{array}{l}\text { AGOS } \\
\text { AEL106W }\end{array}$ & Fructose-2,6-bisphosphatase (AgFBP26) & c. $103 C>T$ & p.R35W & 21 & 23 & 0.523 \\
\hline $\mathrm{Vl}$ & 96,950 & A & C & 1088.19 & missense & $\begin{array}{l}\text { AGOS } \\
\text { AFL185W }\end{array}$ & $\begin{array}{l}\text { Beta subunit of phosphofructokinase } \\
\text { (AgPFK2) }\end{array}$ & C.1963A > C & p.N655H & 35 & 37 & 0.514 \\
\hline $\mathrm{Vl}$ & 97,509 & AT & A & 907.15 & frameshift & $\begin{array}{l}\text { AGOS } \\
\text { AFL185W }\end{array}$ & $\begin{array}{l}\text { Beta subunit of phosphofructokinase } \\
\text { (AgPFK2) }\end{array}$ & c.2526Tdel & p.Phe842fs & 20 & 32 & 0.615 \\
\hline \multicolumn{13}{|l|}{ TCA cycle } \\
\hline 1 & 346,384 & G & A & 758.19 & missense & $\begin{array}{l}\text { AGOS } \\
\text { AARO04C }\end{array}$ & Citrate synthase (AgCIT1) & $c .68 \mathrm{C}>\mathrm{T}$ & р.T23M & 18 & 25 & 0.581 \\
\hline 1 & 634,291 & G & T & 991.19 & Nonsense & $\begin{array}{l}\text { AGOS } \\
\text { AAR162C }\end{array}$ & Pyruvate carboxylase (AgPYC2) & $c .3266 c>A$ & p.S1089* & 31 & 33 & 0.514 \\
\hline I & 634,669 & A & T & 836.19 & missense & $\begin{array}{l}\text { AGOS } \\
\text { AAR162C }\end{array}$ & Pyruvate carboxylase (AgPYC2) & $\begin{array}{l}\text { c.2888 T > } \\
\text { A }\end{array}$ & p.L963Q & 21 & 26 & 0.553 \\
\hline III & 238,489 & $\mathrm{~T}$ & G & 729.19 & missense & $\begin{array}{l}\text { AGOS } \\
\text { ACL065C }\end{array}$ & $\begin{array}{l}\text { Iron-sulfur protein subunit of succinate } \\
\text { dehydrogenase }(\mathrm{AgSDH} 2)\end{array}$ & c.697A > C & p.T233P & 25 & 23 & 0.479 \\
\hline III & 238,962 & G & A & 1051.19 & missense & $\begin{array}{l}\text { AGOS } \\
\text { ACL065C }\end{array}$ & $\begin{array}{l}\text { Iron-sulfur protein subunit of succinate } \\
\text { dehydrogenase }(\mathrm{AgSDH} 2)\end{array}$ & $c .224 \mathrm{C}>\mathrm{T}$ & p.T75M & 20 & 32 & 0.615 \\
\hline III & 451,903 & G & A & 879.19 & missense & $\begin{array}{l}\text { AGOS } \\
\text { ACR052W }\end{array}$ & $\begin{array}{l}\text { Flavoprotein subunit of succinate } \\
\text { dehydrogenase }(\mathrm{AgSDH} 1)^{\mathrm{a}}\end{array}$ & $\begin{array}{l}\text { C.1132G> } \\
\text { A }\end{array}$ & p.D378N & 17 & 27 & 0.614 \\
\hline IV & 403,968 & C & T & 488.19 & missense & $\begin{array}{l}\text { AGOS } \\
\text { ADL164C }\end{array}$ & Malate dehydrogenase (AgMDH2) & C.196G > A & p.A66T & 27 & 16 & 0.372 \\
\hline IV & 644,214 & A & G & 568.19 & missense & $\begin{array}{l}\text { AGOS } \\
\text { ADL032W }\end{array}$ & Aconitase (AgACO1) & $\begin{array}{l}C .1367 A> \\
G\end{array}$ & p.D456G & 10 & 16 & 0.615 \\
\hline V & $\begin{array}{l}1,328 \\
889\end{array}$ & C & A & 922.19 & missense & $\begin{array}{l}\text { AGOS } \\
\text { AER374C }\end{array}$ & $\begin{array}{l}\text { Subunit of the mitochondrial alpha- } \\
\text { ketoglutarate dehydrogenase (AgKGD1) }\end{array}$ & c.1837G > T & p.D613Y & 27 & 27 & 0.5 \\
\hline V & $\begin{array}{l}1,328 \\
948\end{array}$ & G & A & 711.19 & missense & $\begin{array}{l}\text { AGOS }_{-} \\
\text {AER374C }\end{array}$ & $\begin{array}{l}\text { Subunit of the mitochondrial alpha- } \\
\text { ketoglutarate dehydrogenase (AgKGD1) }\end{array}$ & C. $1778 \mathrm{C}>\mathrm{T}$ & p.T593M & 25 & 23 & 0.479 \\
\hline $\mathrm{Vl}$ & 810,404 & G & T & 482.19 & missense & $\begin{array}{l}\text { AGOS } \\
\text { AFR207C }\end{array}$ & $\begin{array}{l}\text { Subunit of succinate dehydrogenase } \\
\text { (AgSDH3) }\end{array}$ & c. $200 C>A$ & p.S67Y & 20 & 18 & 0.473 \\
\hline $\mathrm{Vl}$ & $\begin{array}{l}1,103 \\
105\end{array}$ & G & A & 636.19 & missense & $\begin{array}{l}\text { AGOS } \\
\text { AFR367W }\end{array}$ & Fumarate reductase (AgOSM1) & c. $622 \mathrm{G}>\mathrm{A}$ & p.A208T & 21 & 19 & 0.475 \\
\hline $\mathrm{Vl}$ & $\begin{array}{l}1,585 \\
840\end{array}$ & G & $\mathrm{T}$ & 635.19 & missense & $\begin{array}{l}\text { AGOS } \\
\text { AFR629W }\end{array}$ & Aconitase (AgACO2) & c.1894G > T & p.D632Y & 36 & 24 & 0.400 \\
\hline VII & $\begin{array}{l}1,652 \\
466\end{array}$ & A & G & 970.19 & missense & $\begin{array}{l}\text { AGOS } \\
\text { AGR323C }\end{array}$ & $\begin{array}{l}\text { E3-binding protein of pyruvate } \\
\text { dehydrogenase }(\mathrm{AgPDX} 1)^{a}\end{array}$ & C.677 T > C & p.L226P & 16 & 28 & 0.636 \\
\hline $\mathrm{Vl}$ & 681,082 & C & $\mathrm{T}$ & 624.19 & missense & $\begin{array}{l}\text { AGOS } \\
\text { AFR134C }\end{array}$ & $\begin{array}{l}\text { Alpha subunit of succinyl-CoA ligase } \\
\text { (AgLSC1) }\end{array}$ & C.193G > A & p.A65T & 23 & 24 & 0.510 \\
\hline \multicolumn{13}{|l|}{ Mitochondria } \\
\hline$\|$ & 324,797 & A & G & 633.19 & missense & $\begin{array}{l}\text { AGOS } \\
\text { ABL038W }\end{array}$ & $\begin{array}{l}\text { Mitochondrial aspartate aminotransferase } \\
\text { (AgAAT1) }\end{array}$ & c. $224 \mathrm{~A}>\mathrm{G}$ & p.D75G & 20 & 19 & 0.487 \\
\hline$\|$ & 325,256 & C & $\mathrm{T}$ & 487.19 & missense & $\begin{array}{l}\text { AGOS } \\
\text { ABL038W }\end{array}$ & $\begin{array}{l}\text { Mitochondrial aspartate aminotransferase } \\
\text { (AgAAT1) }\end{array}$ & c. $683 \mathrm{C}>\mathrm{T}$ & p.T228M & 25 & 18 & 0.419 \\
\hline IV & 532,772 & C & A & 1079.19 & missense & $\begin{array}{l}\text { AGOS }_{-} \\
\text {ADL087W }\end{array}$ & Cytochrome b reductase $(\mathrm{AgCBR} 1)^{\mathrm{a}}$ & C. $155 \mathrm{C}>\mathrm{A}$ & p.T52N & 25 & 34 & 0.576 \\
\hline
\end{tabular}


Table 2 Heterozygous mutations in genes involved in metabolisms (Continued)

\begin{tabular}{|c|c|c|c|c|c|c|c|c|c|c|c|c|}
\hline \multirow[t]{2}{*}{ Chromosome } & \multirow[t]{2}{*}{ Position } & \multirow[t]{2}{*}{$\begin{array}{l}\text { Wt } \\
\text { seq. }\end{array}$} & \multirow[t]{2}{*}{$\begin{array}{l}\text { MT } \\
\text { seq }\end{array}$} & \multirow[t]{2}{*}{ Quality } & \multirow[t]{2}{*}{ Mutation } & \multirow[t]{2}{*}{ Gene } & \multirow[t]{2}{*}{ Product } & \multirow[t]{2}{*}{$\begin{array}{l}\text { DNA } \\
\text { changes }\end{array}$} & \multirow[t]{2}{*}{$\begin{array}{l}\text { Protein } \\
\text { changes }\end{array}$} & \multicolumn{2}{|c|}{$\begin{array}{l}\text { Read } \\
\text { number }\end{array}$} & \multirow{2}{*}{$\begin{array}{l}\text { MT } \\
\text { seq. } \\
\text { Ratio }\end{array}$} \\
\hline & & & & & & & & & & $\begin{array}{l}\text { WT } \\
\text { seq. }\end{array}$ & $\begin{array}{l}\text { MT } \\
\text { seq. }\end{array}$ & \\
\hline IV & $\begin{array}{l}1,458 \\
400\end{array}$ & G & $T$ & 559.19 & missense & $\begin{array}{l}\text { AGOS } \\
\text { ADR417W }\end{array}$ & $\begin{array}{l}\text { Mitochondrial aldehyde dehydrogenase } \\
\text { (AgALD4) }\end{array}$ & c. $561 \mathrm{G}>\mathrm{T}$ & p.W187C & 21 & 17 & 0.447 \\
\hline V & $\begin{array}{l}1,227 \\
029\end{array}$ & G & A & 503.19 & missense & $\begin{array}{l}\text { AGOS } \\
\text { AER321W }\end{array}$ & $\begin{array}{l}\text { Mitochondrial D-lactate dehydrogenase } \\
\text { (AgDLD1) }^{a}\end{array}$ & c. $190 \mathrm{G}>\mathrm{A}$ & p.A64T & 11 & 15 & 0.577 \\
\hline $\mathrm{VI}$ & 899,775 & G & A & 668.19 & missense & $\begin{array}{l}\text { AGOS_}_{-} \\
\text {AFR255W }\end{array}$ & $\begin{array}{l}\text { Mitochondrial tRNA translation optimization } \\
1 \text { (MTO1) }^{a}\end{array}$ & $\begin{array}{l}\text { c. } 1423 G> \\
A\end{array}$ & p.G475S & 27 & 22 & 0.449 \\
\hline $\mathrm{VI}$ & $\begin{array}{l}1,243 \\
899\end{array}$ & C & T & 819.19 & missense & $\begin{array}{l}\text { AGOS } \\
\text { AFR447C }\end{array}$ & $\begin{array}{l}\text { NADH:ubiquinone oxidoreductase (AgNDI1) } \\
\text { a }\end{array}$ & $c .943 G>A$ & p.V315M & 16 & 26 & 0.619 \\
\hline VII & $\begin{array}{l}1,441 \\
269\end{array}$ & C & A & 874.19 & missense & $\begin{array}{l}\text { AGOS } \\
\text { AGR196W }\end{array}$ & Glutathione-disulfide reductase (AgGLR1) a & c. $1415 C>A$ & p.S472Y & 27 & 28 & 0.509 \\
\hline \multicolumn{13}{|c|}{ Riboflavin metabolism } \\
\hline$\|$ & 194,781 & G & T & 733.19 & missense & $\begin{array}{l}\text { AGOS } \\
\text { ABL109W }\end{array}$ & Riboflavin kinase (AgFMN1) & $\mathrm{c} .80 \mathrm{G}>\mathrm{T}$ & p.S27l & 20 & 22 & 0.524 \\
\hline IV & 182,017 & G & A & 687.19 & missense & $\begin{array}{l}\text { AGOS } \\
\text { ADL296C }\end{array}$ & GTP cyclohydrolase II (AgRIB1) & c. $230 \mathrm{C}>\mathrm{T}$ & p.P77L & 23 & 23 & 0.500 \\
\hline \multicolumn{13}{|c|}{ Glycine, serine, threonine metabolism } \\
\hline । & 448,391 & G & A & 962.19 & missense & $\begin{array}{l}\text { AGOS } \\
\text { AAR059C }\end{array}$ & Threonine synthase (AgTHR4) & c.685C $>\mathrm{T}$ & p.R229W & 19 & 29 & 0.604 \\
\hline III & 125,457 & G & A & 821.19 & missense & $\begin{array}{l}\mathrm{AGOS}_{-} \\
\mathrm{ACL} 130 \mathrm{C}\end{array}$ & Phosphoserine phosphatase (AgSER2) & c. $140 \mathrm{C}>\mathrm{T}$ & p.A47V & 28 & 27 & 0.491 \\
\hline III & 727,688 & C & T & 572.19 & missense & $\begin{array}{l}\text { AGOS } \\
\text { ACR215C }\end{array}$ & Serine hydroxymethyltransferase (AgSHM2) & c.593G > A & p.R198Q & 24 & 20 & 0.455 \\
\hline VII & $\begin{array}{l}1,057 \\
290\end{array}$ & T & C & 592.19 & missense & $\begin{array}{l}\text { AGOS }_{-} \\
\text {AGR012C }\end{array}$ & Cystathionine beta-synthase (AgCYS4) & c. $269 \mathrm{~A}>\mathrm{G}$ & p.K90R & 16 & 19 & 0.543 \\
\hline VII & $\begin{array}{l}1,446, \\
998\end{array}$ & A & G & 720.19 & missense & $\begin{array}{l}\text { AGOS }_{-} \\
\text {AGR200W }\end{array}$ & Threonine aldolase (AgGLY1) & $\begin{array}{l}C .1088 \mathrm{~A}> \\
\mathrm{G}\end{array}$ & p.Y363C & 14 & 20 & 0.588 \\
\hline
\end{tabular}

Branched-chain amino acid metabolism

\begin{tabular}{|c|c|c|c|c|c|c|c|c|c|c|c|c|}
\hline I & 305,862 & G & A & 960.19 & missense & $\begin{array}{l}\text { AGOS }_{-} \\
\text {AAL021W }\end{array}$ & $\begin{array}{l}\text { Small subunit of acetohydroxyacid synthase } \\
\text { (AglLV6) }\end{array}$ & c. $140 \mathrm{G}>\mathrm{A}$ & p.S47N & 25 & 29 & 0.537 \\
\hline I & 305,877 & G & A & 923.19 & missense & $\begin{array}{l}\text { AGOS }_{-} \\
\text {AALO21W }\end{array}$ & $\begin{array}{l}\text { Small subunit of acetohydroxyacid synthase } \\
\text { (AglLV6) }\end{array}$ & c.155G > A & p.S52N & 28 & 30 & 0.517 \\
\hline I & 306,395 & G & $\mathrm{T}$ & 711.19 & missense & $\begin{array}{l}\text { AGOS } \\
\text { AAL021W }\end{array}$ & $\begin{array}{l}\text { Small subunit of acetohydroxyacid synthase } \\
\text { (AglLV6) }\end{array}$ & c.673G $>$ T & p.G225C & 23 & 22 & 0.489 \\
\hline$\|$ & 729,493 & G & A & 1028.19 & missense & $\begin{array}{l}\text { AGOS } \\
\text { ABR174W }\end{array}$ & $\begin{array}{l}\text { Branched-chain amino acid biosynthesis } \\
\text { activator (AgLEU3) }\end{array}$ & c.704G > A & p.G235D & 23 & 33 & 0.589 \\
\hline$\|$ & 730,278 & G & A & 915.19 & missense & $\begin{array}{l}\text { AGOS }_{-} \\
\text {ABR174W }\end{array}$ & $\begin{array}{l}\text { Branched-chain amino acid biosynthesis } \\
\text { activator (AgLEU3) }\end{array}$ & $\begin{array}{l}\text { C.1489G > } \\
\text { A }\end{array}$ & p.A497T & 22 & 26 & 0.542 \\
\hline VI & 12,855 & C & A & 543.19 & missense & $\begin{array}{l}\text { AGOS } \\
\text { AFL229W }\end{array}$ & 2-isopropylmalate synthase (AgLEU4) & c. $1051 C>A$ & p.P351T & 26 & 19 & 0.422 \\
\hline VII & $\begin{array}{l}1,381 \\
676\end{array}$ & C & $\mathrm{T}$ & 564.19 & missense & $\begin{array}{l}\text { AGOS } \\
\text { AGR169W }\end{array}$ & 3-isopropylmalate dehydratase (LEU1) & c. $226 C>T$ & p.H76Y & 12 & 17 & 0.586 \\
\hline VII & $\begin{array}{l}1,382 \\
933\end{array}$ & $\mathrm{~T}$ & C & 745.19 & missense & $\begin{array}{l}\text { AGOS } \\
\text { AGR169W }\end{array}$ & 3-isopropylmalate dehydratase (LEU1) & $\begin{array}{l}\text { C.1483T> } \\
\text { C }\end{array}$ & p.S495P & 26 & 25 & 0.490 \\
\hline \multicolumn{13}{|c|}{ romatic amino acid metabolism } \\
\hline$\|$ & 206,627 & C & $\mathrm{T}$ & 580.19 & missense & $\begin{array}{l}\text { AGOS- } \\
\text { ABL102C }\end{array}$ & $\begin{array}{l}\text { 3-deoxy-D-arabino-heptulosonate-7- } \\
\text { phosphate (DAHP) synthase (AgARO3) }\end{array}$ & $c .935 G>A$ & p.C312Y & 28 & 18 & 0.391 \\
\hline ॥ & 799,743 & C & A & 554.19 & missense & $\begin{array}{l}\text { AGOS } \\
\text { ABR209W }\end{array}$ & Anthranilate synthase (AgTRP2) & c. $982 C>A$ & p.L328I & 15 & 16 & 0.516 \\
\hline $\mathrm{VI}$ & $\begin{array}{l}1,313 \\
765\end{array}$ & T & A & 750.19 & missense & $\begin{array}{l}\text { AGOS } \\
\text { AFR485C }\end{array}$ & Tryptophan synthase (AgTRP5) & c. $1917 A>T$ & p.Q639H & 33 & 29 & 0.468 \\
\hline $\mathrm{VI}$ & $\begin{array}{l}1,426 \\
745\end{array}$ & G & $\mathrm{T}$ & 476.19 & missense & $\begin{array}{l}\text { AGOS } \\
\text { AFR548C }\end{array}$ & Aromatic aminotransferase I (AgARO8) & C. $544 C>A$ & p.P182T & 29 & 16 & 0.356 \\
\hline
\end{tabular}


Table 2 Heterozygous mutations in genes involved in metabolisms (Continued)

\begin{tabular}{|c|c|c|c|c|c|c|c|c|c|c|c|c|}
\hline \multirow[t]{2}{*}{ Chromosome } & \multirow[t]{2}{*}{ Position } & \multirow[t]{2}{*}{$\begin{array}{l}\text { Wt } \\
\text { seq. }\end{array}$} & \multirow[t]{2}{*}{$\begin{array}{l}\text { MT } \\
\text { seq }\end{array}$} & \multirow[t]{2}{*}{ Quality } & \multirow[t]{2}{*}{ Mutation } & \multirow[t]{2}{*}{ Gene } & \multirow[t]{2}{*}{ Product } & \multirow[t]{2}{*}{$\begin{array}{l}\text { DNA } \\
\text { changes }\end{array}$} & \multirow[t]{2}{*}{$\begin{array}{l}\text { Protein } \\
\text { changes }\end{array}$} & \multicolumn{2}{|c|}{$\begin{array}{l}\text { Read } \\
\text { number }\end{array}$} & \multirow{2}{*}{$\begin{array}{l}\text { MT } \\
\text { seq. } \\
\text { Ratio }\end{array}$} \\
\hline & & & & & & & & & & $\begin{array}{l}\text { WT } \\
\text { seq. }\end{array}$ & $\begin{array}{l}\text { MT } \\
\text { seq. }\end{array}$ & \\
\hline VII & $\begin{array}{l}1,157 \\
861\end{array}$ & G & A & 690.19 & missense & $\begin{array}{l}\text { AGOS } \\
\text { AGR066W }\end{array}$ & $\begin{array}{l}\text { Pentafunctional aromatic polypeptide } \\
\text { (AgARO1) }\end{array}$ & $\begin{array}{l}\text { C.3536G > } \\
\text { A }\end{array}$ & p.R1179H & 22 & 21 & 0.488 \\
\hline VII & $\begin{array}{l}1,158 \\
247\end{array}$ & G & A & 921.19 & missense & $\begin{array}{l}\text { AGOS } \\
\text { AGR066W }\end{array}$ & $\begin{array}{l}\text { Pentafunctional aromatic polypeptide } \\
\text { (AgARO1) }\end{array}$ & $\begin{array}{l}\text { C.3922G > } \\
\text { A }\end{array}$ & p.G1308S & 29 & 31 & 0.517 \\
\hline \multicolumn{13}{|c|}{ Sulfur amino acid metabolism } \\
\hline । & 361,523 & G & A & 834.19 & missense & $\begin{array}{l}\text { AGOS } \\
\text { AARO10W }\end{array}$ & $\begin{array}{l}\text { Transcriptional activator of sulfur } \\
\text { metabolism (AgMET28) }\end{array}$ & c.719G > A & p.R240Q & 28 & 25 & 0.472 \\
\hline$\|$ & 259,309 & $C$ & T & 578.19 & missense & $\begin{array}{l}\text { AGOS } \\
\text { ABL077W }\end{array}$ & $\underset{\text { Ba }}{\text { Beta subunit of sulfite reductase (AgMET5) }}$ & c. $3002 C>T$ & p.A1001V & 25 & 19 & 0.432 \\
\hline$\|$ & 804,448 & C & T & 685.19 & missense & $\begin{array}{l}\text { AGOS } \\
\text { ABR212C }\end{array}$ & $\begin{array}{l}\text { Cobalamin-independent methionine } \\
\text { synthase (AgMET6) }\end{array}$ & c.499G > A & p.G167S & 25 & 23 & 0.479 \\
\hline III & 259,886 & $C$ & A & 1053.19 & missense & $\begin{array}{l}\text { AGOS } \\
\text { ACL059C }\end{array}$ & $\begin{array}{l}\text { Peroxisomal cystathionine beta-lyase } \\
\text { (AgSTR3) }\end{array}$ & $c .1210 G>T$ & p.V404L & 16 & 32 & 0.667 \\
\hline III & 585,577 & C & A & 547.19 & missense & $\begin{array}{l}\text { AGOS } \\
\text { ACR134W }\end{array}$ & Folylpolyglutamate synthetase (AgMET7) & c. $1135 C>A$ & p.L379M & 25 & 17 & 0.405 \\
\hline IV & 646,485 & G & A & 838.19 & missense & $\begin{array}{l}\text { AGOS } \\
\text { ADL031W }\end{array}$ & $\begin{array}{l}\text { O-acetyl homoserine-O-acetyl serine sulfhy- } \\
\text { drylase (AgMET17) }\end{array}$ & c.302G > A & p.G101D & 23 & 26 & 0.531 \\
\hline V & $\begin{array}{l}1,338 \\
633\end{array}$ & G & A & 974.19 & missense & $\begin{array}{l}\text { AGOS } \\
\text { AER377C }\end{array}$ & $\begin{array}{l}\text { Component of cytosolic iron-sulfur protein } \\
\text { assembly machinery (AgMET18) }\end{array}$ & c. $1061 C>T$ & p.T354l & 28 & 31 & 0.525 \\
\hline $\mathrm{VI}$ & $\begin{array}{l}1,699 \\
984\end{array}$ & C & A & 936.19 & missense & $\begin{array}{l}\text { AGOS } \\
\text { AFR682C }\end{array}$ & L-homoserine-O-acetyltransferase (AgMET2) & $c .1045 G>T$ & p.A349S & 20 & 32 & 0.615 \\
\hline $\mathrm{Vl}$ & $\begin{array}{l}1,720 \\
007\end{array}$ & C & T & 393.19 & missense & $\begin{array}{l}\text { AGOS } \\
\text { AFR692C }\end{array}$ & $\begin{array}{l}\text { S-adenosylmethionine synthetase } \\
\text { (AgSAM2) }\end{array}$ & $c .731 G>A$ & p.G244D & 30 & 13 & 0.302 \\
\hline VII & $\begin{array}{l}1,511 \\
391\end{array}$ & C & A & 892.19 & missense & $\begin{array}{l}\text { AGOS } \\
\text { AGR237C }\end{array}$ & $\begin{array}{l}\text { Alpha subunit of assimilatory sulfite } \\
\text { reductase (AgMET10) }\end{array}$ & $c .2268 \mathrm{G}>\mathrm{T}$ & p.E756D & 22 & 28 & 0.560 \\
\hline VII & $\begin{array}{l}1,512 \\
792\end{array}$ & C & A & 606.19 & missense & $\begin{array}{l}\text { AGOS }_{-} \\
\text {AGR237C }\end{array}$ & $\begin{array}{l}\text { Alpha subunit of assimilatory sulfite } \\
\text { reductase (AgMET10) }\end{array}$ & $c .867 \mathrm{G}>\mathrm{T}$ & p.E289D & 27 & 22 & 0.449 \\
\hline VII & $\begin{array}{l}1,685 \\
571\end{array}$ & G & A & 715.19 & missense & $\begin{array}{l}\text { AGOS } \\
\text { AGR343W }\end{array}$ & $\begin{array}{l}\text { Component of cytosolic iron-sulfur protein } \\
\text { assembly (CIA) machinery }\end{array}$ & c. $563 G>A$ & p.R188H & 24 & 21 & 0.467 \\
\hline \multicolumn{13}{|c|}{ Other amino acid metabolism } \\
\hline III & 169,882 & C & $\mathrm{T}$ & 367.19 & missense & $\begin{array}{l}\text { AGOS } \\
\text { ACL096W }\end{array}$ & Proline utilization transactivator (AgPUT3) & c. $382 C>T$ & p.R128W & 26 & 14 & 0.350 \\
\hline IV & 98,235 & C & A & 727.19 & missense & $\begin{array}{l}\text { AGOS } \\
\text { ADL346W }\end{array}$ & Alpha-aminoadipate reductase (AgLYS2) & c. $1648 \mathrm{C}>\mathrm{A}$ & p.L550M & 27 & 23 & 0.460 \\
\hline $\mathrm{VI}$ & $\begin{array}{l}1,397 \\
559\end{array}$ & C & A & 864.19 & missense & $\begin{array}{l}\text { AGOS } \\
\text { AFR534W }\end{array}$ & $\begin{array}{l}\text { Small subunit of carbamoyl phosphate } \\
\text { synthetase (AgCPA1) }\end{array}$ & c. $976 C>A$ & p.P326T & 29 & 25 & 0.463 \\
\hline VII & 389,521 & C & A & 724.19 & missense & $\begin{array}{l}\text { AGOS } \\
\text { AGL165W }\end{array}$ & Proline oxidase (AgPUT1) ${ }^{a}$ & c. $104 C>A$ & p.T35K & 28 & 24 & 0.462 \\
\hline VII & $\begin{array}{l}1,708 \\
538\end{array}$ & T & G & 528.19 & missense & $\begin{array}{l}\text { AGOS } \\
\text { AGR357W }\end{array}$ & Asparaginase (AgASP1) & $c .311 \mathrm{~T}>\mathrm{G}$ & p.l104R & 19 & 17 & 0.472 \\
\hline \multicolumn{13}{|c|}{ Purine, pyrimidine nulceotide metabolism } \\
\hline । & 558,677 & G & A & 532.19 & missense & $\begin{array}{l}\text { AGOS }_{-} \\
\text {AAR120C }\end{array}$ & $\begin{array}{l}\text { Phosphoribosyl-glycinamide transformylase } \\
\text { (AgADE8) }\end{array}$ & c. $218 C>T$ & p.T73| & 16 & 16 & 0.500 \\
\hline$\|$ & 269,595 & C & A & 593.19 & missense & $\begin{array}{l}\text { AGOS } \\
\text { ABL070C }\end{array}$ & $\begin{array}{l}\text { Xanthine-guanine phosphoribosyl } \\
\text { transferase (AgXPT1) }\end{array}$ & $c .232 \mathrm{G}>\mathrm{T}$ & p.D78Y & 29 & 22 & 0.431 \\
\hline$\|$ & 784,947 & G & A & 618.19 & missense & $\begin{array}{l}\mathrm{AGOS}_{-} \\
\mathrm{ABR} 204 \mathrm{C}\end{array}$ & AMP deaminase (AgAMD1) & c. $1553 C>T$ & p.T5181 & 38 & 21 & 0.356 \\
\hline III & 132,857 & C & A & 773.19 & missense & $\begin{array}{l}\text { AGOS } \\
\text { ACL121C }\end{array}$ & $\begin{array}{l}\text { Trifunctional C1-tetrahydrofolate synthase } \\
\text { (AgADE3) }\end{array}$ & c. $2067 \mathrm{G}>\mathrm{T}$ & p.R689S & 21 & 25 & 0.543 \\
\hline III & 214,069 & A & T & 441.19 & missense & $\begin{array}{l}\text { AGOS } \\
\text { ACL077C }\end{array}$ & Ribose-5-phosphate isomerase (AgRKI1) & c. $17 \mathrm{~T}>\mathrm{A}$ & p.16N & 29 & 17 & 0.370 \\
\hline III & 636,192 & A & T & 711.19 & missense & $\begin{array}{l}\text { AGOS }_{-} \\
\text {ACR160C }\end{array}$ & $\begin{array}{l}\text { Nicotinate phosphoribosyltransferase } \\
\text { (AgNPT1) }\end{array}$ & $\mathrm{C} .84 \mathrm{~T}>\mathrm{A}$ & p.N28K & 26 & 24 & 0.480 \\
\hline
\end{tabular}


Table 2 Heterozygous mutations in genes involved in metabolisms (Continued)

\begin{tabular}{|c|c|c|c|c|c|c|c|c|c|c|c|c|}
\hline \multirow[t]{2}{*}{ Chromosome } & \multirow[t]{2}{*}{ Position } & \multirow[t]{2}{*}{$\begin{array}{l}\text { Wt } \\
\text { seq. }\end{array}$} & \multirow[t]{2}{*}{$\begin{array}{l}\text { MT } \\
\text { seq }\end{array}$} & \multirow[t]{2}{*}{ Quality } & \multirow[t]{2}{*}{ Mutation } & \multirow[t]{2}{*}{ Gene } & \multirow[t]{2}{*}{ Product } & \multirow[t]{2}{*}{$\begin{array}{l}\text { DNA } \\
\text { changes }\end{array}$} & \multirow[t]{2}{*}{$\begin{array}{l}\text { Protein } \\
\text { changes }\end{array}$} & \multicolumn{2}{|c|}{$\begin{array}{l}\text { Read } \\
\text { number }\end{array}$} & \multirow{2}{*}{$\begin{array}{l}\text { MT } \\
\text { seq. } \\
\text { Ratio }\end{array}$} \\
\hline & & & & & & & & & & $\begin{array}{l}\overline{W T} \\
\text { seq. }\end{array}$ & $\begin{array}{l}\text { MT } \\
\text { seq. }\end{array}$ & \\
\hline III & 654,234 & C & $\mathrm{T}$ & 690.19 & missense & $\begin{array}{l}\text { AGOS } \\
\text { ACR170C }\end{array}$ & Uridylate kinase (AgURA6) & C. $152 \mathrm{G}>\mathrm{A}$ & p.R51H & 14 & 21 & 0.600 \\
\hline III & 715,325 & G & T & 697.19 & missense & $\begin{array}{l}\text { AGOS } \\
\text { ACR210C }\end{array}$ & $\begin{array}{l}\text { Phosphoribosylaminoimidazole carboxylase } \\
\text { (AgADE2) }\end{array}$ & C. $926 C>A$ & p.A309D & 23 & 21 & 0.477 \\
\hline III & 832,220 & C & T & 957.19 & missense & $\begin{array}{l}\text { AGOS } \\
\text { ACR263C }\end{array}$ & $\begin{array}{l}\text { Bifunctional carbamoylphosphate } \\
\text { synthetase/aspartate transcarbamylase } \\
\text { (AgURA2) }\end{array}$ & $\begin{array}{l}\text { C.2275G > } \\
\text { A }\end{array}$ & p.E759K & 19 & 31 & 0.620 \\
\hline III & 832,428 & C & T & 745.19 & missense & $\begin{array}{l}\text { AGOS } \\
\text { ACR263C }\end{array}$ & $\begin{array}{l}\text { Bifunctional carbamoylphosphate } \\
\text { synthetase/aspartate transcarbamylase } \\
\text { (AgURA2) }\end{array}$ & $\begin{array}{l}\text { C.2067G > } \\
\text { A }\end{array}$ & p.M689| & 27 & 23 & 0.460 \\
\hline IV & 580,072 & G & T & 461.19 & missense & $\begin{array}{l}\text { AGOS }_{-} \\
\text {ADL057W }\end{array}$ & $\begin{array}{l}\text { Large subunit of ribonucleotide reductase } \\
\text { (AgRNR1) }\end{array}$ & c. $2520 \mathrm{G}>\mathrm{T}$ & p.K840N & 16 & 15 & 0.483 \\
\hline V & 792,520 & T & C & 1069.19 & missense & $\begin{array}{l}\text { AGOS } \\
\text { AER083C }\end{array}$ & $\begin{array}{l}\text { 5-phospho-ribosyl-1-pyrophosphate } \\
\text { synthetase (AgPRS1) }\end{array}$ & c. $488 \mathrm{~A}>\mathrm{G}$ & p.Q163R & 24 & 33 & 0.578 \\
\hline $\mathrm{Vl}$ & 896,312 & $A$ & T & 502.19 & missense & $\begin{array}{l}\text { AGOS } \\
\text { AFR254C }\end{array}$ & $\begin{array}{l}\text { Aminoimidazole ribotide synthetase and } \\
\text { glycinamide ribotide synthetase (AgADE5,7) }\end{array}$ & $\begin{array}{l}\text { C.1654T> } \\
\text { A }\end{array}$ & p.L552I & 20 & 15 & 0.428 \\
\hline $\mathrm{Vl}$ & 978,821 & C & A & 584.19 & missense & $\begin{array}{l}\text { AGOS } \\
\text { AFR297W }\end{array}$ & Myb-related transcription factor (AgBAS1) & c. $905 C>A$ & p.P302H & 23 & 20 & 0.465 \\
\hline VII & 108,330 & G & A & 674.19 & missense & $\begin{array}{l}\text { AGOS } \\
\text { AGL320C }\end{array}$ & CTP synthase (AgURA7) & c. $1361 C>T$ & p.T454l & 23 & 25 & 0.521 \\
\hline VII & 430,379 & G & A & 703.19 & missense & $\begin{array}{l}\text { AGOS } \\
\text { AGL146W }\end{array}$ & GTP cyclohydrolase (AgURC1) & $\begin{array}{l}\text { C.1247G > } \\
\text { A }\end{array}$ & p.G416D & 27 & 21 & 0.4 \\
\hline VII & $\begin{array}{l}1,072 \\
826\end{array}$ & T & c & 377.19 & missense & $\begin{array}{l}\text { AGOS }_{-} \\
\text {AGR022C }\end{array}$ & $\begin{array}{l}\text { Nicotinic acid mononucleotide } \\
\text { adenylyytransferase (AgNMA1) }\end{array}$ & $c .814 A>G$ & p.T272A & 26 & 13 & 0.3 \\
\hline
\end{tabular}

Fatty acid metabolism

\begin{tabular}{|c|c|c|c|c|c|c|c|c|c|c|c|c|}
\hline I & 564,702 & G & A & 769.19 & missense & $\begin{array}{l}\text { AGOS } \\
\text { AAR124C }\end{array}$ & Carnitine acetyl-CoA transferase (AgCAT2) & c. $1736 C>T$ & p.S579F & 19 & 23 & 0.548 \\
\hline IV & $\begin{array}{l}1,430 \\
996\end{array}$ & G & A & 829.19 & missense & $\begin{array}{l}\text { AGOS } \\
\text { ADR403C }\end{array}$ & $\begin{array}{l}\text { Oleate-activated transcription factor } \\
\text { (AgOAF1 or AgPIP2) }\end{array}$ & c. $1405 C>T$ & p.R469C & 22 & 26 & 0.542 \\
\hline IV & $\begin{array}{l}1,436 \\
329\end{array}$ & G & $\mathrm{T}$ & 757.19 & missense & $\begin{array}{l}\text { AGOS } \\
\text { ADR405C }\end{array}$ & $\begin{array}{l}\text { Oleate-activated transcription factor } \\
\text { (AgOAF1 or AgPIP2) }\end{array}$ & c. $2170 C>A$ & p.L724l & 35 & 28 & 0.444 \\
\hline IV & $\begin{array}{l}1,437 \\
793\end{array}$ & G & A & 800.19 & $\begin{array}{l}\text { stop_ } \\
\text { gained }\end{array}$ & $\begin{array}{l}\text { AGOS } \\
\text { ADR405C }\end{array}$ & $\begin{array}{l}\text { Oleate-activated transcription factor } \\
\text { (AgOAF1 or AgPIP2) }\end{array}$ & c.706C $>\mathrm{T}$ & p.Q236* & 30 & 25 & 0.455 \\
\hline IV & $\begin{array}{l}1,443 \\
883\end{array}$ & $\mathrm{~T}$ & A & 729.19 & nonsense & $\begin{array}{l}\text { AGOS }_{-} \\
\text {ADR408W }\end{array}$ & Acetyl-coA synthetase (AgACS1) & $\begin{array}{l}\text { C.1128T> } \\
\text { A }\end{array}$ & p.Tyr376* & 21 & 23 & 0.523 \\
\hline V & 794,683 & T & C & 631.19 & missense & $\begin{array}{l}\text { AGOS } \\
\text { AER085C }\end{array}$ & $\begin{array}{l}\text { Beta subunit of fatty acid synthetase } \\
\text { (AgFAS1) }^{a}\end{array}$ & $\begin{array}{l}C .5837 A> \\
G\end{array}$ & p.K1946R & 23 & 19 & 0.452 \\
\hline V & 797,843 & T & G & 419.19 & missense & $\begin{array}{l}\text { AGOS } \\
\text { AER085C }\end{array}$ & $\begin{array}{l}\text { Beta subunit of fatty acid synthetase } \\
\text { (AgFAS1) }^{a}\end{array}$ & c. $2677 A>C$ & p.K893Q & 38 & 15 & 0.283 \\
\hline V & 797,858 & C & A & 1299.19 & missense & $\begin{array}{l}\text { AGOS } \\
\text { AER085C }\end{array}$ & $\begin{array}{l}\text { Beta subunit of fatty acid synthetase } \\
\text { (AgFAS1) }^{a}\end{array}$ & c. $2662 \mathrm{G}>\mathrm{T}$ & p.D888Y & 14 & 38 & 0.731 \\
\hline VI & 172,719 & A & $\mathrm{T}$ & 746.19 & missense & $\begin{array}{l}\text { AGOS } \\
\text { AFL138W }\end{array}$ & $\begin{array}{l}\text { Alpha subunit of fatty acid synthetase } \\
\text { (AgFAS2) }\end{array}$ & $c .7 A>T$ & p.M3L & 19 & 26 & 0.578 \\
\hline VI & 175,856 & C & A & 656.19 & missense & $\begin{array}{l}\text { AGOS } \\
\text { AFL138W }\end{array}$ & $\begin{array}{l}\text { Alpha subunit of fatty acid synthetase } \\
\text { (AgFAS2) }\end{array}$ & c. $3144 C>A$ & p.F1048L & 21 & 21 & 0.500 \\
\hline VI & $\begin{array}{l}1,507 \\
650\end{array}$ & $\mathrm{~T}$ & A & 742.19 & missense & $\begin{array}{l}\text { AGOS } \\
\text { AFR592W }\end{array}$ & $\begin{array}{l}\text { 1-acyl-sn-glycerol-3-phosphate } \\
\text { acyltransferase (AgSLC1) }\end{array}$ & c.832A $>\mathrm{T}$ & p.L278M & 21 & 22 & 0.512 \\
\hline VII & 421,657 & G & $\mathrm{T}$ & 728.19 & missense & $\begin{array}{l}\text { AGOS } \\
\text { AGL148C }\end{array}$ & Acetyl-coA synthetase (AgACS2) & c. $772 \mathrm{C}>\mathrm{A}$ & p.Q258K & 24 & 24 & 0.500 \\
\hline VII & 422,089 & C & $\mathrm{T}$ & 804.19 & missense & $\begin{array}{l}\text { AGOS } \\
\text { AGL148C }\end{array}$ & Acetyl-coA synthetase (AgACS2) & c. $340 \mathrm{G}>\mathrm{A}$ & p.A114T & 25 & 26 & 0.510 \\
\hline VII & 913,244 & C & A & 553.19 & missense & $\begin{array}{l}\text { AGOS } \\
\text { AGL060W }\end{array}$ & $\begin{array}{l}\text { 3-hydroxyacyl-CoA dehydrogenase and } \\
\text { enoyl-CoA hydratase (AgFOX2) }\end{array}$ & C. $814 C>A$ & p.P272T & 25 & 17 & 0.405 \\
\hline
\end{tabular}


Table 2 Heterozygous mutations in genes involved in metabolisms (Continued)

\begin{tabular}{|c|c|c|c|c|c|c|c|c|c|c|c|c|}
\hline \multirow[t]{2}{*}{ Chromosome } & \multirow[t]{2}{*}{ Position } & \multirow[t]{2}{*}{$\begin{array}{l}\text { Wt } \\
\text { seq. }\end{array}$} & \multirow[t]{2}{*}{$\begin{array}{l}\text { MT } \\
\text { seq }\end{array}$} & \multirow[t]{2}{*}{ Quality } & \multirow[t]{2}{*}{ Mutation } & \multirow[t]{2}{*}{ Gene } & \multirow[t]{2}{*}{ Product } & \multirow[t]{2}{*}{$\begin{array}{l}\text { DNA } \\
\text { changes }\end{array}$} & \multirow[t]{2}{*}{$\begin{array}{l}\text { Protein } \\
\text { changes }\end{array}$} & \multicolumn{2}{|c|}{$\begin{array}{l}\text { Read } \\
\text { number }\end{array}$} & \multirow{2}{*}{$\begin{array}{l}\text { MT } \\
\text { seq. } \\
\text { Ratio }\end{array}$} \\
\hline & & & & & & & & & & $\begin{array}{l}\text { WT } \\
\text { seq. }\end{array}$ & $\begin{array}{l}\text { MT } \\
\text { seq. }\end{array}$ & \\
\hline \multicolumn{13}{|c|}{ Heme biosynthesis } \\
\hline । & 380,486 & A & C & 573.19 & missense & $\begin{array}{l}\text { AGOS } \\
\text { AAR021W }\end{array}$ & Protoporphyrinogen oxidase (AgHEM14) ${ }^{a}$ & C.617A >C & p.E206A & 30 & 21 & 0.412 \\
\hline$\|$ & 203,080 & T & C & 1002.19 & missense & $\begin{array}{l}\text { AGOS }_{-} \\
\text {ABL104C }\end{array}$ & 5-aminolevulinate synthase (AgHEM1) & $\begin{array}{l}C .1397 A> \\
G\end{array}$ & p.E466G & 18 & 31 & 0.633 \\
\hline V & $\begin{array}{l}1,281 \\
270\end{array}$ & T & A & 552.19 & nonsense & $\begin{array}{l}\text { AGOS } \\
\text { AER351W }\end{array}$ & Uroporphyrinogen-III synthase (AgHEM4) & c.762T>A & p.Y254* & 19 & 20 & 0.513 \\
\hline VII & $\begin{array}{l}1,608, \\
654\end{array}$ & A & AG & 453.15 & frameshift & $\begin{array}{l}\text { AGOS } \\
\text { AGR298C }\end{array}$ & $\begin{array}{l}\text { S-adenosyl-L-methionine uroporphyrinogen } \\
\text { III transmethylase (AgMET1) }\end{array}$ & c.1412dupC & p.A472fs & 19 & 19 & 0.500 \\
\hline \multicolumn{13}{|c|}{ Other flavoprotein } \\
\hline III & 660,436 & G & T & 853.19 & missense & $\begin{array}{l}\text { AGOS } \\
\text { ACR175W }\end{array}$ & Sulfhydryl oxidase (AgERV2) a & $c .441 G>T$ & p.W147C & 28 & 28 & 0.500 \\
\hline IV & 94,090 & G & A & 485.19 & missense & $\begin{array}{l}\text { AGOS } \\
\text { ADL348W }\end{array}$ & Endoplasmic oxidoreductin1 (AgERO1) ${ }^{a}$ & c.386G > A & p.S129N & 20 & 18 & 0.474 \\
\hline \multicolumn{13}{|c|}{ Folate metabolism } \\
\hline VII & $\begin{array}{l}1,665 \\
459\end{array}$ & G & A & 658.19 & missense & $\begin{array}{l}\text { AGOS } \\
\text { AGR330W }\end{array}$ & Aminodeoxychorismate lyase (AgABZ2) & c. $208 \mathrm{G}>\mathrm{A}$ & p.V70M & 29 & 23 & 0.442 \\
\hline VII & $\begin{array}{l}1,674 \\
504\end{array}$ & $C$ & A & 813.19 & missense & $\begin{array}{l}\text { AGOS } \\
\text { AGR335C }\end{array}$ & GTP-cyclohydrolase I (AgFOL2) & c.343G > T & p.D115Y & 30 & 25 & 0.455 \\
\hline
\end{tabular}

These heterozygous mutations are a subset among all 1382 heterozygous mutations which are shown in Table S2

aFlavoproteins

*Translation stops here

mutations were also detected in genes involved in heme biosynthesis and sulfur metabolism (Table 2).

We detected homozygous mutations in the AgSHM2, AgARO2, AgILV2, and AgLYS5 genes involved in amino acid biosynthesis (Table 1). Heterozygous mutations in genes involved in amino acid metabolism were concentrated in glycine, serine, and threonine metabolism; branched-chain amino acid biosynthesis; and aromatic amino acid biosynthesis (Table 2). In our previous study, the increased expression of AgTRP2 (ABR209W) and AgTRP5 (AFR485C) was observed in MT strain by a proteomic analysis. AgTRP2 and AgTRP5 are annotated as anthranilate synthase and tryptophan synthase, respectively, which belong to the tryptophan biosynthetic pathway. These results suggest that these amino acid metabolic pathways may be linked to riboflavin production in A. gossypii.

Several heterozygous mutations were detected in genes involved in sulfur amino acid metabolism. In particular, the sulfur amino acid biosynthesis pathway contains

Table 3 Number of mutated genes encoding flavoproteins

\begin{tabular}{lllll}
\hline & Total $^{\mathrm{a}}$ & Homozygous & Heterozygous & Mutation rate \\
\hline FAD-dependent & 36 & $1(1)$ & $11(9)$ & $33.3 \%$ \\
FMN-dependent & 16 & $1(1)$ & $2(1)$ & $18.8 \%$
\end{tabular}

${ }^{a}$ Total number of each flavoproteins is showed based on the reference by Gudipati et al. [42]

Each bracket indicates the number of mutated genes encoding

mitochondrial proteins heterozygously mutated genes in the MT strain $\{A g M E T 5$ (AGOS_ABL077W), AgMET6 (AGOS_ABR212C), AgSTR3 (AGOS_ACL059C), AgMET17 (AGOS ADL031W), AgMET2 (AGOS_AFR682C), AgSAM2 (AGOS_AFR692C), AgMET10 (AGOS_AGR237C) . Mainly, genes encoding all enzymes that catalyze homocysteine in $S$. cerevisiae, except the adenosylhomocysteinase encoded by the AgSAH1 gene, were heterozygously mutated. These results suggest that methionine metabolism, which consists of one-carbon metabolism together with folate metabolism, may be associated with riboflavin production in A. gossypii. The AgMET10 and AgMET5 genes encode alpha and beta subunits of sulfite reductase in S. cerevisiae, respectively, which are both flavoproteins.

It was previously reported that riboflavin production in A. gossypii was improved by disruption of the AgURA3 gene, which leads to blockage of the pyrimidine biosynthetic pathway in this organism [33]. In the MT strain, several genes in the pyrimidine biosynthetic pathway have heterozygous mutations (Table 2). These results suggest that pyrimidine metabolism, including the pyrimidine de novo and salvage pathways, may be associated with riboflavin production in A. gossypii. In the purine biosynthetic pathway, the AgRKI1 (AGOS ACL077C), AgRPS1 (AGOS_AER083C), AgADE5,7 (AGOS_AFR254C), AgADE8 (AGOS_AAR120C), and AgADE2 (AGOS_ACR210C) genes have heterozygous mutations in the MT strain. Moreover, the AgBAS1 gene 
(AGOS_AFR297W), which encodes the transcription factor for regulation of the purine and glycine biosynthesis pathways in A. gossypii [45], also has one heterozygous mutation. These heterozygous mutations may partially force the restriction of purine biosynthesis, which is important for riboflavin production in A. gossypii. This limited purine biosynthesis in A. gossypii was also reported by Ledesma-Amaro et al., who showed the downregulation of purine biosynthesis during riboflavin production [43].

In addition to mutations in genes involved in metabolic pathways in A. gossypii, 17 heterozygous mutations in genes involved in DNA repair were detected (Table 4). In particular, genes involved in mismatch DNA repair $\{A g M S H 2$ (AGOS_AAL093C), AgMSH3 (AGOS_ADR168C), AgMSH6
(AGOS_AGR116W), AgMLH1 (AGOS_AFL199C), $A g M L H 2$ (AGOS_AFR226C), AgMLH3 (AGOS_AAL093C), and AgPMS1 (AGOS_AER421W)\} were heterozygously mutated. These proteins function cooperatively to repair DNA mismatches in S. cerevisiae. Among MutS homologs, genes encoding AgMSH2, AgMSH3 and AgMSH6 had heterozygous mutations, but no mutation was detected in genes encoding AgMSH1, AgMSH4 and AgMSH5. ScMSH2, ScMSH3 and ScMSH6 of S. cerevisiae function to maintain nuclear genome stability [46]. In contrast, ScMSH1 functions in mitochondria, and ScMSH4 and ScMSH5 function during meiosis $[47,48]$. These results suggest that the heterologous mutations in AgMSH2, AgMSH3 and AgMSH6 may compromise the DNA mismatch repair pathway and contribute to the maintenance of DNA mismatches and

Table 4 Heterozygous mutations in genes involved in DNA repair

\begin{tabular}{|c|c|c|c|c|c|c|c|c|c|c|c|c|}
\hline \multirow[t]{2}{*}{ Chromosome } & \multirow[t]{2}{*}{ Position } & \multirow{2}{*}{$\begin{array}{l}\text { WT } \\
\text { seq. }\end{array}$} & \multirow{2}{*}{$\begin{array}{l}\text { MT } \\
\text { seq }\end{array}$} & \multirow[t]{2}{*}{ Quality } & \multirow[t]{2}{*}{ Mutation } & \multirow[t]{2}{*}{ Gene } & \multirow[t]{2}{*}{ Product } & \multirow{2}{*}{$\begin{array}{l}\text { DNA } \\
\text { changes }\end{array}$} & \multirow{2}{*}{$\begin{array}{l}\text { Protein } \\
\text { changes }\end{array}$} & \multicolumn{2}{|c|}{ Read number } & \multirow{2}{*}{$\begin{array}{l}\text { MT } \\
\text { seq } \\
\text { ratio }\end{array}$} \\
\hline & & & & & & & & & & $\begin{array}{l}\text { WT } \\
\text { seq. }\end{array}$ & $\begin{array}{l}\text { MT } \\
\text { seq. }\end{array}$ & \\
\hline । & 177,825 & G & $\mathrm{T}$ & 533.19 & missense & $\begin{array}{l}\text { AGOS } \\
\text { AAL093C }\end{array}$ & $\begin{array}{l}\text { DNA mismatch repair protein } \\
\text { (AgMLH3) }\end{array}$ & $\begin{array}{l}\text { C.1516C> } \\
\text { A }\end{array}$ & p.L506M & 22 & 17 & 0.436 \\
\hline IV & 997,942 & $\mathrm{~T}$ & G & 729.19 & missense & $\begin{array}{l}\text { AGOS } \\
\text { ADR168C }\end{array}$ & $\begin{array}{l}\text { DNA mismatch repair protein } \\
\text { (AgMSH3) }\end{array}$ & $\begin{array}{l}\text { C.2937A > } \\
\text { C }\end{array}$ & p.K979N & 39 & 23 & 0.371 \\
\hline IV & 998,607 & G & A & 982.19 & nonsense & $\begin{array}{l}\text { AGOS } \\
\text { ADR168C }\end{array}$ & $\begin{array}{l}\text { DNA mismatch repair protein } \\
\text { (AgMSH3) }\end{array}$ & $\begin{array}{l}\text { c. } 2272 C> \\
T\end{array}$ & p.Q758* & 22 & 29 & 0.569 \\
\hline IV & $\begin{array}{l}1,446 \\
658\end{array}$ & G & T & 747.19 & missense & $\begin{array}{l}\text { AGOS } \\
\text { ADR411W }\end{array}$ & Checkpoint protein (AgRAD17) & c.358G $>\mathrm{T}$ & p.D120Y & 32 & 24 & 0.429 \\
\hline V & 486,710 & G & A & 711.19 & missense & $\begin{array}{l}\text { AGOS } \\
\text { AEL075W }\end{array}$ & $\begin{array}{l}\text { DNA polymerase delta subunit } 3 \\
\text { (AgPOL32) }\end{array}$ & $\begin{array}{l}\text { C.490G > } \\
\text { A }\end{array}$ & p.A164T & 18 & 22 & 0.550 \\
\hline V & $\begin{array}{l}1,239 \\
357\end{array}$ & C & A & 411.19 & missense & $\begin{array}{l}\text { AGOS } \\
\text { AER327C }\end{array}$ & $\begin{array}{l}\text { Uracil-DNA glycosylase } \\
\text { (AgUNG1) }\end{array}$ & c.757G > T & p.A253S & 27 & 16 & 0.372 \\
\hline V & $\begin{array}{l}1,445 \\
972\end{array}$ & G & A & 869.19 & missense & $\begin{array}{l}\text { AGOS } \\
\text { AER421W }\end{array}$ & $\begin{array}{l}\text { DNA mismatch repair protein } \\
\text { (AgPMS1) }\end{array}$ & $\begin{array}{l}\text { C.1762G> } \\
\text { A }\end{array}$ & p.A588T & 23 & 28 & 0.549 \\
\hline $\mathrm{Vl}$ & 65,368 & C & T & 587.19 & missense & $\begin{array}{l}\text { AGOS } \\
\text { AFL199C }\end{array}$ & $\begin{array}{l}\text { DNA mismatch repair protein } \\
\text { (AgMLH1) }\end{array}$ & $\begin{array}{l}\text { C.320G > } \\
\text { A }\end{array}$ & p.C107Y & 20 & 20 & 0.500 \\
\hline VI & 677,447 & G & A & 967.19 & nonsense & $\begin{array}{l}\text { AGOS } \\
\text { AFR133C }\end{array}$ & $\begin{array}{l}\text { single-stranded DNA } \\
\text { endonuclease (AgRAD2) }\end{array}$ & $\begin{array}{l}C .2143 C> \\
T\end{array}$ & p.Q715* & 25 & 30 & 0.545 \\
\hline VI & 677,525 & $C$ & A & 743.19 & missense & $\begin{array}{l}\text { AGOS } \\
\text { AFR133C }\end{array}$ & $\begin{array}{l}\text { single-stranded DNA } \\
\text { endonuclease (AgRAD2) }\end{array}$ & $\begin{array}{l}\text { c. } 2065 G> \\
T\end{array}$ & p.D689Y & 27 & 28 & 0.509 \\
\hline VI & 834,113 & A & G & 889.19 & missense & $\begin{array}{l}\text { AGOS } \\
\text { AFR220W }\end{array}$ & $\begin{array}{l}\text { DNA helicase/Ubiquitin ligase } \\
\text { (AgRAD5) }\end{array}$ & $\begin{array}{l}c .2419 A> \\
G\end{array}$ & p.S807G & 18 & 25 & 0.581 \\
\hline VI & 834,860 & G & T & 678.19 & nonsense & $\begin{array}{l}\text { AGOS }_{-} \\
\text {AFR22OW }\end{array}$ & $\begin{array}{l}\text { DNA helicase/Ubiquitin ligase } \\
\text { (AgRAD5) }\end{array}$ & $\begin{array}{l}\text { c.3166G > } \\
T\end{array}$ & p.E1056* & 29 & 22 & 0.431 \\
\hline VI & 848,262 & A & G & 828.19 & missense & $\begin{array}{l}\text { AGOS } \\
\text { AFR226C }\end{array}$ & $\begin{array}{l}\text { DNA mismatch repair protein } \\
(\mathrm{AgMLH} 2)\end{array}$ & $\begin{array}{l}\text { c. } 1882 \\
T>C\end{array}$ & p.F628L & 26 & 31 & 0.544 \\
\hline VI & $\begin{array}{l}1,528 \\
970\end{array}$ & $C$ & T & 1142.19 & nonsense & $\begin{array}{l}\text { AGOS } \\
\text { AFR603C }\end{array}$ & $\begin{array}{l}\text { DNA mismatch repair protein } \\
(\mathrm{AgMSH} 2)\end{array}$ & $\begin{array}{l}\text { C.2711G }> \\
\text { A }\end{array}$ & p.W904* & 18 & 36 & 0.667 \\
\hline VI & $\begin{array}{l}1,529 \\
553\end{array}$ & G & A & 1151.19 & missense & $\begin{array}{l}\text { AGOS } \\
\text { AFR603C }\end{array}$ & $\begin{array}{l}\text { DNA mismatch repair protein } \\
\text { (AgMSH2) }\end{array}$ & $\begin{array}{l}\text { C. } 2128 C> \\
T\end{array}$ & p.P710S & 12 & 33 & 0.733 \\
\hline VII & $\begin{array}{l}1,278 \\
725\end{array}$ & T & G & 786.19 & missense & $\begin{array}{l}\text { AGOS } \\
\text { AGR116W }\end{array}$ & $\begin{array}{l}\text { DNA mismatch repair protein } \\
\text { (AgMSH6) }\end{array}$ & $\begin{array}{l}c .1005 \\
T>G\end{array}$ & p.N335K & 24 & 25 & 0.510 \\
\hline VII & $\begin{array}{l}1,368 \\
167\end{array}$ & $C$ & T & 788.19 & missense & $\begin{array}{l}\text { AGOS }_{-} \\
\text {AGR162C }^{2}\end{array}$ & DNA repair protein (AgRAD4) & $\begin{array}{l}\text { C. } 1214 G> \\
A\end{array}$ & p.R405Q & 17 & 23 & 0.575 \\
\hline
\end{tabular}


accumulation of heterologous mutations in the genome of A. gossypii during disparity mutagenesis and rapid evolution of $A$. gossypii to the riboflavin-overproducing mutant MT strain. Previous papers have shown that heterologous mutations of the ScMSH2 gene showed mutator phenotypes in diploid yeasts and suppression of the mismatch repair pathway and proofreading-deficient DNA polymerase $\varepsilon$ in human cells, leading to the accumulation of numerous mutations $[49,50]$. However, the riboflavin production level in MT was stable during 14 passages [13].

As mentioned above, MT strain never produced its haploid spores. Some heterozygous mutations were found in genes involved in the sporulation (Table 5). Two putative 1,3- $\beta$-D-glucan synthase genes (AGOS ACL181C, AGOS_AAR053W) had heterozygous mutations. Especially, AGOS_AAR053W had one frameshift mutation which may have great influences on the protein function. In $S$. cerevisiae, FKS2 is a $1,3-\beta$-D-glucan synthase during its sporulation and FKS2 and FKS3 works in spore wall assembly [51]. In addition, FKS2 binds to a sporulation-specific kinase, SMK1 [52]. Heterozygous mutations of AGOS_ACL181C and AGOS_ AAR053W may have some influences on the sporulation in MT strain. Moreover, we found heterozygous mutations in AgIME2 (AGOS_AFR076W) and AgKAR4 (AGOS_ AFR736C) genes. Disruption of AgIME2 gene or AgKAR4 gene leads to the deficiency of its sporulation in A. gossypii [53]. These heterozygous mutations may also be one of the reasons for the sporulation deficiency in MT strain.

Gene Ontology (GO) enrichment analysis was performed (Supplementary materials Tables S3, S4 and S5) in the set of genes containing homozygous or heterozygous mutations. Over-represented GO terms are ATP binding, Protein binding and ATPase activity. Especially, in "ATP binding", all 22 ATP-dependent helicase genes have a single heterologous mutation, respectively. It was recently reported that RNA helicases have the relationship with aging and life span of cells [54]. Mutations of all RNA helicase genes support the suggestion that riboflavin production in A. gossypii may be associated with the aging of cells. Interestingly, we also found 25 mutated genes among 139 genes in "oxidation-reduction process" (Supplementary materials Table S3) and no mutated gene was in "mitochondrion". This result suggests that oxidative stress is more associated with the riboflavin overproduction in MT strain than the mitochondrial dysfunction and supports the previous study showing a riboflavin-overproducing A. gossypii mutant is vulnerable to photoinduced oxidative DNA damage and accumulate ROS [23], leading to the aging of cells. On the other hand, "Ribosome", "Translation", "Structural constituent of ribosome" and "Intracellular" were under-represented. These GO terms contain ribosomal proteins involved in translation (Supplementary materials Tables S5). Mutations of genes encoding these proteins are lethal in organisms and, therefore, these GO terms were under-presented.

\section{Effect of temperature on riboflavin production in MT strain} By genomic analysis of the MT strain, one homozygous mutation in the AgHSP104 gene (AGOS_AGL036C), which causes a nonsense mutation, was detected (Table 1). This mutation generates the mutated AgHSP104, composed of 355 amino acid residues at its $\mathrm{N}$-terminus. HSP104 in fungi contributes to the thermotolerance and disaggregation of denatured and aggregated proteins, ethanol tolerance and survival in the stationary phase [55]. We confirmed this nonsense mutation in the MT strain by DNA sequencing (Fig. 3a). In addition, other four homozygous mutations in the MT strain were also confirmed by DNA sequencing (Data not shown). These results validate the results of the genomic analysis. The WT and MT strains were cultivated on YD medium at 28 and $37^{\circ} \mathrm{C}$. The growth and riboflavin production in WT cultivated at $37^{\circ} \mathrm{C}$ were slightly lower than those in WT cultivated at $28^{\circ} \mathrm{C}$ (Fig. 3b). However, the growth of and riboflavin production in the MT strain were dramatically reduced at $37^{\circ} \mathrm{C}$ compared to those at $30^{\circ} \mathrm{C}$, and the MT strain was not able to grow normally. These results reflected the generation of truncated AgHSP104 in the MT strain, leading to loss of thermotolerance, even at $37^{\circ} \mathrm{C}$. This result also confirms the presence of the homozygous mutation in the AgHSP104 gene of the MT strain. Which corresponds, a homozygous missense mutation was found in AgPMT1 gene (AGOS_ADR279C) (Supplementary materials Table S1). This encodes a putative $O$-mannosyltransferase which is essential for the cell wall integrity by $O$-glycosylation of cell wall mannoproteins. In Aspergillus, the disruption of the genes caused the high sensitivity of growth temperature and low cell wall integrity $[56,57]$. This mutation may also partially contribute to the high sensitivity of growth temperature in MT strain.

\section{Effect of iron for the riboflavin production in MT strain}

In Tables 2 and 3, many heterozygous mutations were detected in genes encoding proteins involved in mitochondrial function and DNA. Iron-sulfur $(\mathrm{Fe} / \mathrm{S})$ clusters are required for TCA cycles, the electron transfer chain and fatty acid oxidation in mitochondria and DNA repair in nucleus $[58,59]$. Therefore, the addition of iron ion for the MT strain cultivation was investigated. $\mathrm{Fe}^{3+}$ enhanced the growth of mycelia and riboflavin production in the MT strain (Fig. 4a) also in the presence of glycine, which is well-known for the improvement of the riboflavin production in A. gossypii. Addition of $\mathrm{Fe}^{3+}$ and $\mathrm{Fe}^{3+}+$ glycine improved the riboflavin production of MT strain by 1.6 and 2.0 fold, respectively although we were not able to find its significant differences. (Fig. 4b). 
Table 5 Heterozygous mutations in genes involved in sporulation

\begin{tabular}{|c|c|c|c|c|c|c|c|c|c|c|c|c|}
\hline \multirow[t]{2}{*}{ Chromosome } & \multirow[t]{2}{*}{ Position } & \multirow[t]{2}{*}{$\begin{array}{l}\text { WT } \\
\text { seq. }\end{array}$} & \multirow[t]{2}{*}{$\begin{array}{l}\text { MT } \\
\text { seq }\end{array}$} & \multirow[t]{2}{*}{ Quality } & \multirow[t]{2}{*}{ Mutation } & \multirow[t]{2}{*}{ Gene } & \multirow[t]{2}{*}{ Product } & \multirow[t]{2}{*}{$\begin{array}{l}\text { DNA } \\
\text { changes }\end{array}$} & \multirow[t]{2}{*}{$\begin{array}{l}\text { Protein } \\
\text { changes }\end{array}$} & \multicolumn{2}{|c|}{$\begin{array}{l}\text { Read } \\
\text { number }\end{array}$} & \multirow{2}{*}{$\begin{array}{l}\text { MT } \\
\text { seq } \\
\text { ratio }\end{array}$} \\
\hline & & & & & & & & & & $\begin{array}{l}\text { WT } \\
\text { seq. }\end{array}$ & $\begin{array}{l}\text { MT } \\
\text { seq. }\end{array}$ & \\
\hline III & 41,510 & $\mathrm{~T}$ & G & 1253.19 & missense & $\begin{array}{l}\text { AGOS } \\
\text { ACL181C }\end{array}$ & $\begin{array}{l}\text { 1,3-beta-D-glucan synthase } \\
\text { (AgFKS1 or AgGSC2) }\end{array}$ & C. $4596 \mathrm{~A}>\mathrm{C}$ & p.Lys1532Asn & 23 & 37 & 0.617 \\
\hline ॥ & 101,053 & $\mathrm{~T}$ & G & 878.19 & missense & $\begin{array}{l}\text { AGOS } \\
\text { ABL159W }\end{array}$ & $\begin{array}{l}\text { Component of the septin ring } \\
\text { (AgSHS1) }\end{array}$ & c.1229 T > G & p.lle410Ser & 20 & 29 & 0.592 \\
\hline IV & 649,360 & G & A & 886.19 & missense & $\begin{array}{l}\text { AGOS } \\
\text { ADL029W }\end{array}$ & $\begin{array}{l}\text { Component of the meiotic outer } \\
\text { plaque of the spindle pole body } \\
\text { (AgSPO74) }\end{array}$ & c.374G > A & p.Ser125Asn & 19 & 26 & 0.578 \\
\hline V & 965,295 & A & ACAG & 1023.15 & $\begin{array}{l}\text { disruptive } \\
\text { inframe_- } \\
\text { insertion }\end{array}$ & $\begin{array}{l}\text { AGOS } \\
\text { AER177W }\end{array}$ & $\begin{array}{l}\text { Transcription factor targeting } \\
\text { filamentation genes (AgTEC 1) }\end{array}$ & $\begin{array}{l}\text { c.1518 } \\
\text { 1520dupGCA }\end{array}$ & p.Gln507dup & 21 & 28 & 0.571 \\
\hline IV & $\begin{array}{l}1,263 \\
702\end{array}$ & G & $\mathrm{T}$ & 982.19 & missense & $\begin{array}{l}\text { AGOS }_{-} \\
\text {ADR317C }\end{array}$ & Dual-specificity kinase (AgMPS1) & c. $2228 \mathrm{C}>\mathrm{A}$ & p.Thr743Asn & 24 & 31 & 0.564 \\
\hline VI & $\begin{array}{l}1,158 \\
992\end{array}$ & A & G & 1022.19 & missense & $\begin{array}{l}\text { AGOS } \\
\text { AFR400C }\end{array}$ & $\mathrm{N}$-formyltyrosine oxidase (AgDIT2) & c.635 T > C & p.lle212Thr & 25 & 32 & 0.561 \\
\hline III & 48,243 & C & A & 765.19 & missense & $\begin{array}{l}\text { AGOS } \\
\text { ACL179C }\end{array}$ & Meiosis-specific protein (AgSPO77) & c. $1601 G>T$ & p.Arg534lle & 18 & 23 & 0.561 \\
\hline VI & $\begin{array}{l}1,225 \\
184\end{array}$ & A & $\mathrm{C}$ & 753.19 & missense & $\begin{array}{l}\text { AGOS }_{-} \\
\text {AFR436C }\end{array}$ & $\begin{array}{l}\text { Component of the septin ring } \\
\text { (AgCDC11) }\end{array}$ & c.371 T> G & p.Val124Gly & 21 & 25 & 0.543 \\
\hline । & 436,519 & A & AT & 935.15 & frameshift & $\begin{array}{l}\text { AGOS } \\
\text { AAR053W }\end{array}$ & $\begin{array}{l}\text { 1,3-beta-D-glucan synthase } \\
\text { (AgGSC2 or AgFKS1 or AgFKS3) }\end{array}$ & $\begin{array}{l}\text { c.916_ } \\
\text { 917insT }\end{array}$ & p.Arg306fs & 24 & 28 & 0.538 \\
\hline $\mathrm{VI}$ & $\begin{array}{l}1,531 \\
918\end{array}$ & T & C & 659.19 & missense & $\begin{array}{l}\text { AGOS } \\
\text { AFR604C }\end{array}$ & $\begin{array}{l}\text { Component of the meiotic outer } \\
\text { plaque of the spindle pole body } \\
\text { (AgSPO21) }\end{array}$ & c. $2531 A>G$ & p.Gln844Arg & 18 & 20 & 0.526 \\
\hline VI & $\begin{array}{l}1,288 \\
694\end{array}$ & G & $\mathrm{T}$ & 943.19 & missense & $\begin{array}{l}\text { AGOS }_{-} \\
\text {AFR469W }\end{array}$ & t-SNARE protein (AgSEC9) & c.918G > T & p.Glu306Asp & 27 & 29 & 0.518 \\
\hline $\mathrm{VI}$ & 672,483 & C & T & 645.19 & missense & $\begin{array}{l}\text { AGOS } \\
\text { AFR130W }\end{array}$ & $\begin{array}{l}\text { Protein involved in the control of } \\
\text { meiotic nuclear division (AgSSP1) }\end{array}$ & c. $121 \mathrm{C}>\mathrm{T}$ & p.Leu41Phe & 20 & 21 & 0.512 \\
\hline IV & $\begin{array}{l}1,456 \\
401\end{array}$ & G & T & 500.19 & missense & $\begin{array}{l}\text { AGOS } \\
\text { ADR416W }\end{array}$ & $\begin{array}{l}\text { Mitotic exit network scaffold } \\
\text { protein (AgNUD1) }\end{array}$ & c. $1263 G>T$ & p.Gln $421 \mathrm{His}$ & 16 & 16 & 0.500 \\
\hline VI & 639,702 & C & $\mathrm{T}$ & 610.19 & missense & $\begin{array}{l}\text { AGOS } \\
\text { AFR111C }\end{array}$ & $\begin{array}{l}\text { Component of the septin ring } \\
\text { (AgCDC3) }\end{array}$ & c. $203 \mathrm{G}>\mathrm{A}$ & p.Gly68Asp & 22 & 22 & 0.500 \\
\hline VII & $\begin{array}{l}1,087 \\
176\end{array}$ & G & A & 676.19 & missense & $\begin{array}{l}\text { AGOS }_{-} \\
\text {AGRO31W }\end{array}$ & $\begin{array}{l}\text { Transcriptional repressor (AgNRG1 } \\
\text { or AgNRG2) }\end{array}$ & c. $107 \mathrm{G}>\mathrm{A}$ & p.Ser36Asn & 25 & 24 & 0.490 \\
\hline VI & $\begin{array}{l}1,225 \\
449\end{array}$ & A & T & 596.19 & missense & $\begin{array}{l}\text { AGOS } \\
\text { AFR436C }\end{array}$ & $\begin{array}{l}\text { Component of the septin ring } \\
\text { (AgCDC11) }\end{array}$ & c. $106 \mathrm{~T}>\mathrm{A}$ & p.Ser36Thr & 25 & 21 & 0.457 \\
\hline V & $\begin{array}{l}1,436 \\
486\end{array}$ & G & A & 466.19 & missense & $\begin{array}{l}\text { AGOS } \\
\text { AER416C }\end{array}$ & $\begin{array}{l}\text { EH domain-containing protein } \\
\text { (AgEND3) }\end{array}$ & c. $4 \mathrm{C}>\mathrm{T}$ & p.Pro2Ser & 21 & 17 & 0.447 \\
\hline VI & 566,815 & A & C & 758.19 & missense & $\begin{array}{l}\text { AGOS } \\
\text { AFR076W }\end{array}$ & $\begin{array}{l}\text { Serine/threonine protein kinase } \\
\text { (AgIME2) }\end{array}$ & C. $1142 A>C$ & p.Tyr381Ser & 30 & 24 & 0.444 \\
\hline IV & $\begin{array}{l}1,423 \\
888\end{array}$ & G & A & 643.19 & missense & $\begin{array}{l}\text { AGOS } \\
\text { ADR400W }\end{array}$ & $\begin{array}{l}\text { Gamma-tubulin small complex } \\
\text { receptor (AgSPC72) }\end{array}$ & c. $278 \mathrm{G}>\mathrm{A}$ & p.Ser93Asn & 24 & 19 & 0.442 \\
\hline IV & 650,376 & A & T & 523.19 & missense & $\begin{array}{l}\text { AGOS }_{-} \\
\text {ADL029W }\end{array}$ & $\begin{array}{l}\text { Component of the meiotic outer } \\
\text { plaque of the spindle pole body } \\
\text { (AgSPO74) }\end{array}$ & c. $1390 A>T$ & p.lle464Phe & 26 & 19 & 0.422 \\
\hline VII & 394,750 & G & A & 560.19 & missense & $\begin{array}{l}\text { AGOS } \\
\text { AGL162C }\end{array}$ & Sm-like protein (AgSEC1) & c. $1972 C>$ T & p.Pro658Ser & 26 & 19 & 0.422 \\
\hline III & 506,687 & $\mathrm{~T}$ & G & 578.19 & missense & $\begin{array}{l}\text { AGOS } \\
\text { ACR083C }\end{array}$ & $\begin{array}{l}\text { Meiosis-specific component of the } \\
\text { spindle pole body (AgDON1 or } \\
\text { AgCUE5) }\end{array}$ & c. $237 \mathrm{~A}>\mathrm{C}$ & p.Arg79Ser & 28 & 18 & 0.391 \\
\hline III & 38,740 & C & A & 576.19 & missense & $\begin{array}{l}\text { AGOS } \\
\text { ACL182C }\end{array}$ & $\begin{array}{l}\text { 1,3-beta-glucanosyltransferase } \\
\text { (AgGAS2) }\end{array}$ & c. $1161 \mathrm{G}>\mathrm{T}$ & p.Glu387Asp & 40 & 21 & 0.344 \\
\hline VI & $\begin{array}{l}1,794 \\
575\end{array}$ & A & C & 577.19 & missense & $\begin{array}{l}\text { AGOS } \\
\text { AFR736C }\end{array}$ & $\begin{array}{l}\text { Transcription factor required for } \\
\text { response to pheromones } \\
\text { (AgKAR4) }\end{array}$ & $c .422 \mathrm{~T}>\mathrm{G}$ & p.Phe141Cys & 46 & 21 & 0.313 \\
\hline
\end{tabular}


(A)

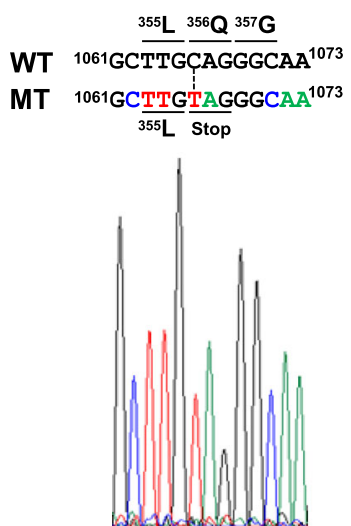

(B)

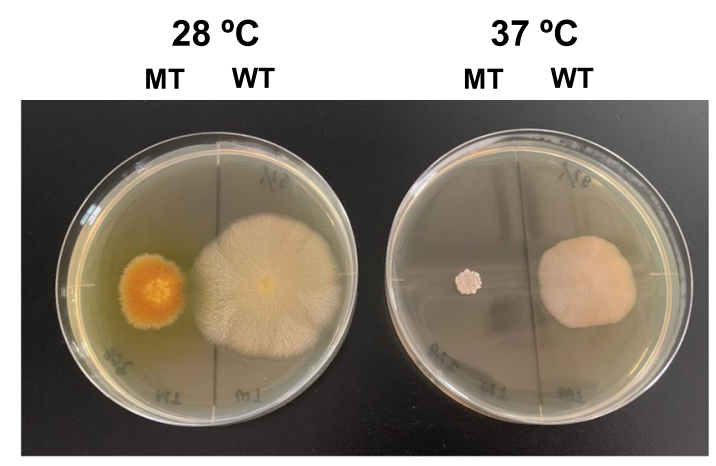

Fig. 3 Growth and riboflavin production of MT strain. a Sequence of AgHSP104 gene in the MT strain. The gene sequence was confirmed by Sanger method. b Growth of and riboflavin production in WT and MT on YD medium at 28 and $37^{\circ} \mathrm{C}$ for $5 \mathrm{~d}$

Specific riboflavin production of MT strain in the presence of $\mathrm{Fe}^{3+}$ and $\mathrm{Fe}^{3+}+$ glycine were also improved by 1.4 and 1.3 fold, respectively although we were not able to find its significant differences. These results indicate that $\mathrm{Fe}^{3+}$ and glycine enhanced the riboflavin production by the improvement of its growth. Flavoproteins in mitochondria of yeasts function in redox processes via the transfer of electrons [41]. In addition, the flavin in flavoproteins participates in iron metabolism. We found two homozygous mutations (AgARO2, AgILV2) and 13 heterozygous mutations (AgSDH1, AgPDX1, AgNDI1, AgDLD1, AgCBR1, AgGLR1, AgMTO1, AgMET5, AgPUT1, AgFAS1, AgHEM14, AgERV2, and AgERO1) in genes encoding putative flavoproteins. Most of these flavoproteins may localized in mitochondria (Tables 1, 2 and 3 ). We previously reported that lactate and pyruvate was produced more in MT strain than WT strain in the minimum medium and succinate was decreased in MT strain compared to WT stain [16]. In addition, gene expression of most of genes involved in TCA cycle was down-regulated in MT strain cultivated compared to WT stain [13]. In Fig. 4, the growth and riboflavin production in MT strain were enhanced by the addition of iron ion, which is involved in mitochondrial functions with flavoproteins $[41,58,59]$. This result also supports the relationship of riboflavin production with the mitochondrial dysfunction. The addition of $\mathrm{Fe}^{2+}$ had no effect on the riboflavin production in WT strain (Data not shown).

\section{Conclusion}

In this study, we analyzed the genomic sequence of the riboflavin-overproducing mutant MT strain and detected some intriguing homozygous and heterozygous mutations in the coding sequences of the MT genome. The homozygous and heterozygous mutations were concentrated in genes encoding proteins involved in the TCA cycle, mitochondrial functions, sulfur metabolism and DNA mismatch repair. The discovery of many heterozygous mutations indicates that mutants with many heterozygous mutations cannot be isolated by conventional mutagenesis methods, such as the use of mutagens and genetic engineering. Disparity mutagenesis is a promising tool for the creation of new types of eukaryotic mutants in various research fields and manufacturing industries. Additionally, the genomic analysis and GO enrichment analysis showed the relationship of the riboflavin production in MT strain with oxidative stress and the aging of cells, supporting the previous result that the accumulation of ROS and DNA damages appeared in other A.gossypii riboflavinoverproducing mutant [23].

\section{Methods}

\section{Strains and cultivation}

A. gossypii ATCC10895, which was purchased from American Type Culture Collection (ATCC), was used as a wild-type strain (WT strain). The A. gossypii w122032 mutant (MT strain) was previously isolated by disparity mutagenesis in the presence of $\mathrm{H}_{2} \mathrm{O}_{2}$, itaconate and oxalate [13] and used as a mutant strain in this study. These strains were maintained at $28^{\circ} \mathrm{C}$ in YD medium ( $1 \%$ yeast extract, $1 \%$ glucose, $\mathrm{pH} 6.8$ ). Chemically defined medium $(15 \mathrm{~g} / \mathrm{L}$ glucose as a carbon source, $1.5 \mathrm{~g} /$ $\mathrm{L}$ asparagine, $0.75 \mathrm{~g} / \mathrm{L} \mathrm{KH}_{2} \mathrm{PO}_{4}, 0.1 \mathrm{~g} / \mathrm{L}$ myo-inositol, $\mathrm{pH}$ 6.8) was used as a minimal medium [16]. To cultivate $A$. gossypii in flasks, mineral ions $\left(4.4 \mathrm{mg} / \mathrm{L} \mathrm{CoCl}_{2} \cdot 6 \mathrm{H}_{2} \mathrm{O}\right.$, $18.0 \mathrm{mg} / \mathrm{L} \quad \mathrm{MnCl}_{2} \cdot 4 \mathrm{H}_{2} \mathrm{O}, 44.0 \mathrm{mg} / \mathrm{L} \mathrm{ZnSO}_{4} \cdot 7 \mathrm{H}_{2} \mathrm{O}, 10.1$ $\mathrm{mg} / \mathrm{L} \quad \mathrm{MgSO}_{4} \cdot 7 \mathrm{H}_{2} \mathrm{O}, 27.0 \mathrm{mg} / \mathrm{L} \mathrm{FeCl}_{3} \cdot 6 \mathrm{H}_{2} \mathrm{O}, 21.9 \mathrm{mg} / \mathrm{L}$ $\mathrm{CaCl}_{2} \cdot 6 \mathrm{H}_{2} \mathrm{O}$, and $2.7 \mathrm{mg} / \mathrm{L} \mathrm{CuSO} \cdot 5 \mathrm{H}_{2} \mathrm{O}$ ) were added to 
(A)
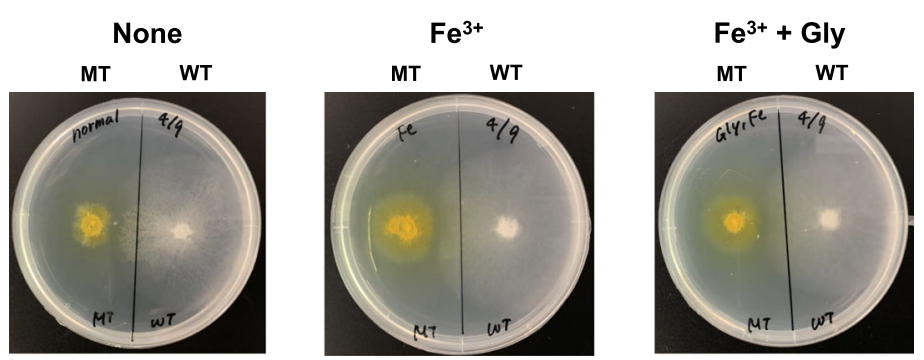

(B)
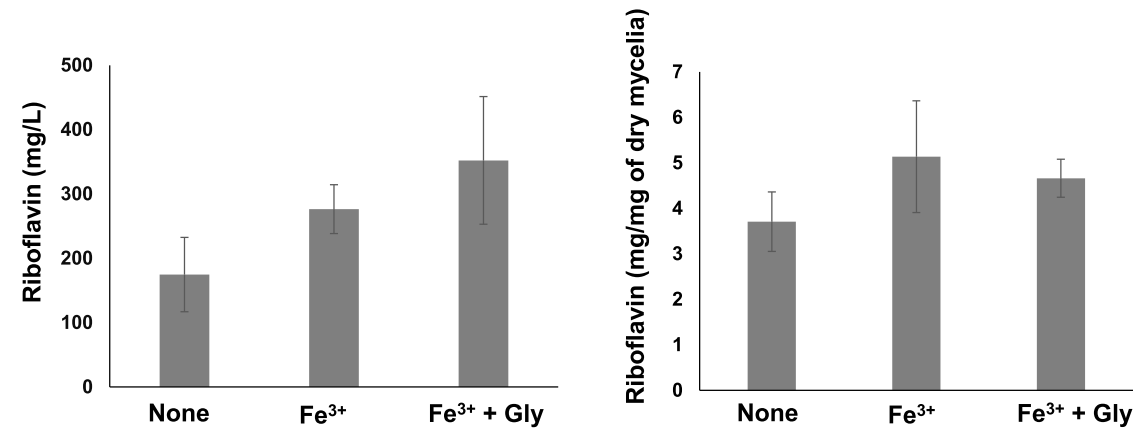

Fig. 4 Growth and riboflavin production in the WT and MT strains in the presence of $\mathrm{Fe}^{3+}$ and glycine. a Growth of WT and MT strains on the minimum medium plate containing $\mathrm{Fe}^{3+}$ and glycine. $\mathrm{Fe}^{3+}$ and glycine were supplemented at $27 \mathrm{mg} / \mathrm{L}$ and $1 \mathrm{mM}$, respectively. b Riboflavin production of MT strain $\mathrm{n}$ minimal medium supplemented with $27 \mathrm{mg} / \mathrm{L} \mathrm{Fe}^{3+}$ and $1 \mathrm{mM}$ glycine. The amount of riboflavin and dry cell was measured at 4 days. Metal ions except for $\mathrm{Fe}^{3+}$ were not supplemented in both cultivations

the minimal medium. Cultivation was carried out using a 500 -ml flask (working volume $50 \mathrm{ml}$ ) with an agitation rate of $120 \mathrm{rpm}$ at $28^{\circ} \mathrm{C}$. The chemically defined medium was used for cultivation on agar plates. Each amino acid was used to supplement the media at $1 \mathrm{mM}$.

\section{Assay}

The amount of riboflavin was determined according to a previous protocol [16]. Briefly, $0.8 \mathrm{~mL}$ of the culture broth was thoroughly mixed with $0.2 \mathrm{~mL}$ of $1 \mathrm{~N} \mathrm{NaOH}$. A $0.4-\mathrm{mL}$ aliquot of the resulting solution was neutralized with $1 \mathrm{~mL}$ of $0.1 \mathrm{M}$ potassium phosphate buffer (pH 6.0), and the absorbance of the solution at a wavelength of $444 \mathrm{~nm}$ was measured. The riboflavin concentration was calculated with an extinction coefficient of $1.04 \times 10^{-2} \mathrm{M}^{-1} \mathrm{~cm}^{-1}$ (127 mg riboflavin/L at ABS444).

\section{Genome analysis}

Genomic DNA was extracted from mycelia cultivated in YD medium during the logarithmic phase using the DNeasy Plant Mini Kit (Qiagen, Venlo, Netherlands) and fragmented using a Covaris Acoustic Solubilizer (Covaris, Woburn, MA, USA). Genomic libraries were prepared using the TruSeq Nano DNA Library Prep Kit (Illumina, San Diego, CA, USA) and sequenced using a MiSeq system (Illumina) at the Instrumental Research Support Office, Research Institute of Green Science and Technology, Shizuoka University.
Paired-end reads $(2 \times 301 \mathrm{bp})$ were cleaned up using Trimmomatic ver. 0.36 [60] by trimming adapter sequences, low-quality reads (quality score, $<15$ ), and the final 301 bases, followed by filtering reads less than $150 \mathrm{bp}$. High-quality reads were aligned to the reference genome of $A$. gossypii ATCC10895 using BWAMEM ver. 0.7.12 [61]. Aligned reads were sorted and duplicates were marked using Picard Tools ver. 2.8.0 (http://broadinstitute.github.io/picard/). The Genome Analysis Toolkit ver. 3.7 [62] was used to call variants, SNPs and short insertions/deletions (indels). The variants identified by HaplotypeCaller in GATK were filtered using Variant Filtration under the following settings: QualByDepth (QD) < 6.0; RMSMappingQuality $(\mathrm{MQ})<50$; Quality $(\mathrm{QUAL})<100$. Annotation of each variant and its functional effect was predicted using SnpEff ver. $4.3 \mathrm{~T}$ [63] with the default database of "Ashbya_gossypii". All proteins of A. gossypii were annotated using HMMER 3.1b2 (http://hmmer.org) against Pfam database 32.0 [64]. GO terms associated with Pfam entries were assigned using the pfam2go mapping file (http://www.geneontology.org/external2 go/pfam2go, version date of 2019/06/01). Two-sided Fisher's exact test was performed to find the GO terms over- and under-represented in the homozygously and heterozygously mutated genes. The significance threshold of over- and under-represented GO terms was defined as a false discovery rate (FDR) of 0.05 . 


\section{Supplementary information}

Supplementary information accompanies this paper at https://doi.org/10. 1186/s12864-020-6709-7.

Additional file 1: Table S1. All 33 homozygous mutations detected in the coding sequences of the MT genome. Table S2. All 1377 heterozygous mutations detected in coding sequences of the MT genome. Table S3. Gene Ontology (GO) enrichment analysis of the genes containing mutations. Table S4. Genes assigned over-represented Gene Ontology. Table S5. Genes assigned under-represented Gene Ontology.

\section{Abbreviations}

AHAS: Acetohydroxyacid synthase; Chr: Chromosome; FAD: Flavin adenine dinucleotide; FDR: False discovery rate; FMN: Favin mononucleotide; GO: Gene ontology; ICL: Isocitrate lyase; indels: insertions/deletions; MQ: RMSMappingQuality; ORF: Open reading frame; PPTase: 4'Phosphopantetheinyl transferase; PRPP: Phosphoribosyl pyrophosphate; QD: QualByDepth; QUAL: Quality; ROS: Reactive oxygen species; SHMT: Serine hydroxymethyltransferase; SNP: Single-nucleotide polymorphisms; SNV: Single-nucleotide variant

\section{Acknowledgements}

Not applicable.

\section{Authors' contributions}

TK, HAE and EYP conceived and designed this research and the experiments. $J A$ and $A Y$ performed the experiments. HD carried out the genomic analysis of the WT and the MT strain. TK, DH and EYP wrote this manuscript. All authors read and approved the final manuscript.

\section{Funding}

This study was supported by the functional strengthening fund of Research Institute of Green Science and Technology, Shizuoka University.

\section{Availability of data and materials}

The raw reads for $A$. gossypii strain WT and MT have been deposited in the DDBJ Sequence Read Archive (DRA) under the accession no. DRA008709. Additionally, they can be also accessed via NCBI (https://www.ncbi.nlm.nih. gov/sra/?term=DRA008709)

\section{Ethics approval and consent to participate}

Not applicable.

\section{Consent for publication}

Not applicable.

\section{Competing interests}

The authors declare that they have no competing interests.

\begin{abstract}
Author details
${ }^{1}$ Green Chemistry Research Division, Research Institute of Green Science and Technology, Shizuoka University, Ohya 836, Suruga-ku, Shizuoka, Japan. ${ }^{2}$ Department of Agriculture, Graduate School of Integrated Science and Technology, Shizuoka University, Ohya 836, Suruga-ku, Shizuoka, Japan. ${ }^{3}$ Instrumental Research Support Office, Research Institute of Green Science and Technology, Shizuoka University, Ohya 836, Suruga-ku, Shizuoka, Japan. ${ }^{4}$ Institute of Bioproduct Development (IBD), Universiti Teknologi Malaysia (UTM), 81310 UTM, Johor Bahru, Malaysia.
\end{abstract}

Received: 29 July 2019 Accepted: 30 March 2020

Published online: 23 April 2020

\section{References}

1. Revuelta JL, Ledesma-Amaro R, Lozano-Martinez P, Díaz-Fernández D, Buey RM, Jiménez A. Bioproduction of riboflavin: a bright yellow history. J Ind Microbiol Biotechnol. 2017;44:659-65.

2. Dietrich FS, Voegeli S, Brachar S, Lerch A, Gates K, Steiner S, Mohr C, Pohlmann R, Luedi P, Choi S, Wing RA, Flavier A, Gaffney TD, Philippsen P.
The Ashbya gossypii genome as a tool for mapping the ancient Saccharomyces cerevisiae genome. Science. 2004;304:304-7.

3. Schmitz HP, Philippsen P. Evolution of multinucleated Ashbya gossypii hyphae from a budding yeast-like ancestor. Fungal Biol. 2011;115:557-68.

4. Schmidt G, Stahmann KP, Kaesler B, Sahm H. Correlation of isocitrate lyase activity and riboflavin formation in the riboflavin overproducer Ashbya gossypii. Microbiology. 1996;142:419-26

5. Sugimoto T, Morimoto A, Nariyama M, Kato T, Park EY. Isolation of an oxalate-resistant Ashbya gossypii stain and its improved riboflavin production. J Ind Microbiol Biotechnol. 2010;37:57-64.

6. Schwechheimer SK, Park EY, Revuelta JL, Becker J, Wittmann C. Biotechnology of riboflavin. App Microbiol Biotechnol. 2016;100:2107-19.

7. Ledesma-Amaro R, Serrano-Amatriain C, Jiménez A, Revuelta JL. Metabolic engineering of riboflavin production in Ashbya gossypii through pathway optimization. Microb Cell Factories. 2015;14:163.

8. Schlüpen C, Santos MA, Weber U, De Graaf A, Revuelta JL, Stahmann KP. Disruption of the SHM2 gene, encoding one of two serine hydroxymethyltransferase isozymes, reduces the flux from glycine to serine in Ashbya gossypii. Biochem J. 2003;369:263-73.

9. Jiménez A, Santos MA, Pompejus M, Revuelta JL. Metabolic engineering of the purine pathway for riboflavin production in Ashbya gossypii. Appl Environ Microbiol. 2005;71:5743-51.

10. Jiménez A, Santos MA, Revuelta JL. Phosphoribosyl pyrophosphate synthetase activity affects growth and riboflavin production in Ashbya gossypii. BMC Biotechnol. 2008;8:67.

11. Schwechheimer SK, Becker J, Peyriga L, Portais JC, Sauer D, Müller R, Hoff B, Haefner S, Schröder H, Zelder O, Wittmann C. Improved riboflavin production with Ashbya gossypii from vegetable oil based on 13C metabolic network analysis with combined labeling analysis by GC/MS, LC/MS, 1D, and 2D NMR. Metab Eng. 2018:47:357-73.

12. Schwechheimer SK, Becker J, Peyriga L, Portais JC, Wittmann C. Metabolic flux analysis in Ashbya gossypii using ${ }^{13} \mathrm{C}$-labeled yeast extract: industrial riboflavin production under complex nutrient conditions. Microb Cell Factories. 2018:17:162

13. Park EY, Ito $Y$, Nariyama M, Sugimoto T, Lies D, Kato T. The improvement of riboflavin production in Ashbya gossypii via disparity mutagenesis and DNA microarray analysis. Appl Microbiol Biotechnol. 2011;91:1315-26.

14. Furusawa M, Doi H. Promotion of evolution: disparity in the frequency of strandspecific misleading between the lagging and leading DNA strands enhances disproportionate accumulation of mutations. J Theor Biol. 1992;157:127-33.

15. Furusawa M, Doi H. Asymmetrical DNA replication promotes evolution: disparity theory of evolution. Genetica. 1998;102:333-47.

16. Jeong BY, Wittmann C, Kato T, Park EY. Comparative metabolic flux analysis of an Ashbya gossypii wild type strain and a high riboflavin-producing mutant strain. J Biosci Bioeng. 2015;119:101-6.

17. Nieland S, Stahmann KP. A developmental stage of hyphal cells shows riboflavin overproduction instead of sporulation in Ashbya gossypii. App Microbiol Biotechnol. 2013;97:10143-53.

18. Philippsen P, Kaufmann A, Schmitz HP. Homologues of yeast polarity genes control the development of multinucleated hyphae in Ashbya gossypii. Curr Opin Microbiol. 2005;8:370-7.

19. Anderson CA, Roberts S, Zhang H, Kelly CM, Kendall A, Lee C, Gerstenberger $J$, Koenig AB, Kabeche R, Gladfelter AS. Ploidy variation in multinucleate cells changes under stress. Mol Biol Cell. 2015;26:1129-40.

20. Ganley AR, Ide S, Saka K, Kobayashi T. The effect of replication initiation on gene amplification in the rDNA and its relationship to aging. Mol Cell. 2009; 35:683-93.

21. Ganley AR, Kobayashi T. Ribosomal DNA and cellular senescence: new evidence supporting the connection between rDNA and aging. FEMS Yeast Res. 2014;14:49-59.

22. Deregowska A, Adamczyk J, Kwiatkowska A, Gurgul A, Skoneczny M, Skoneczna A, Szmatola T, Jasielczuk I, Magda M, Rawska E, Pabian S, Panek A, Kaplan J, Lewinska A, Wnuk M. Shifts in rDNA levels act as a genome buffer promoting chromosome homeostasis. Cell Cycle. 2015;14:3475-87.

23. Silva R, Aguiar TQ, Oliveira R, Domingues L. Light exposure during growth increases riboflavin production, reactive oxygen species accumulation and DNA damage in Ashbya gossypii riboflavin-overproducing strains. FEMS Yeast Res. 2019;19:foy114.

24. Scarsdale JN, Kazanina G, Radaev S, Schirch V, Wright HT. Crystal structure of rabbit cytosolic serine hydroxymethyltransferase at $2.8 \AA$ resolution: mechanistic implications. Biochemistry. 1999;38:8347-58. 
25. Fu TF, Hunt S, Schirch V, Safo MK, Chen BH. Properties of human and rabbit cytosolic serine hydroxymethyltransferase are changed by single nucleotide polymorphic mutations. Arch Biochem Biophys. 2005;442:92-101.

26. Quevillon-Cheruel S, Leulliot N, Meyer P, Graille M, Bremang M, Blondeau K, Sorel I, Poupon A, Janin J, van Tilbeurgh H. Crystal structure of the bifunctional chorismate synthase from Saccharomyces cerevisiae. J Biol Chem. 2004;279:619-25.

27. Pang SS, Duggleby RG. Expression, purification, characterization and reconstitution of the large and small subunits of yeast acetohydroxyacid synthase. Biochemistry. 1999;38:5222-31.

28. Pang SS, Duggleby RG, Guddat LW. Crystal structure of yeast acetohydroxyacid synthase: a target for herbicidal inhibitors. J Mol Biol. 2002;317:1249-62.

29. Ehmann DE, Gehring AM, Walsh CT. Lysine biosynthesis in Saccharomyces cerevisiae: mechanism of a-aminoadipate reductase (Lys2) involves posttranslational phosphopantetheinylationby Lys5. Biochemistry. 1999;38: 6171-7.

30. Kim JM, Song HY, Choi HJ, So KK, Kim DH, Chae KS, Han DM, Jahng KY. Characterization of NpgA, a 4'-phosphopantetheinyl transferase of Aspergillus nidulans, and evidence of its involvement in fungal growth and formation of conidia and cleistothecia for development. J Microbiol. 2015; 53:21-31.

31. Márquez-Fernández O, Trigos A, Ramos-Balderas JL, Viniegra-González G, Deising HB, Aguirre J. Phosphopantetheinyl transferase CfwA/NpgA is required for Aspergillus nidulans secondary metabolism and asexual development. Eukaryot Cell. 2007;6:710-20.

32. Kurt JE, Exinger F, Erbs $P$, Jund R. New insights into the pyrimidine salvage pathway of Saccharomyces cerevisiae: requirement of six genes for cytidine metabolism. Curr Genet. 1999;36:130-6.

33. Silva R, Aguiar TQ, Domingues L. Blockage of the pyrimidine biosynthetic pathway affects riboflavin production in Ashbya gossypii. J Biotechnol. 2015; 193:37-40.

34. Wasserstrom L, Dünkler A, Walther A, Wendland J. The APSES protein Sok2 is a positive regulator of sporulation in Ashbya gossypii. Mol Microbiol. 2017; 106:949-60.

35. Wilkie AO. The molecular basis of genetic dominance. J Med Genet. 1994; 31:89-98.

36. Drabkin M, Birk OS, Birk R. Heterozygous versus homozygous phenotype caused by the same MC4R mutation: novel mutation affecting a large consanguineous kindred. BMC Med Genet. 2018;19:135.

37. Coppin E, Gelsi-Boyer V, Morelli X, Cervera N, Murati A, Pandolfi PP, Birnbaum D, Nunés J. Mutational analysis of the DOK2 haploinsufficient tumor suppressor gene in chronic myelomonocytic leukemia (CMML). Leukemia. 2014;29:500-2.

38. Rizzo JM, Tarsio M, Martínez-Muñoz GA, Kane PM. Diploids heterozygous for a vma13 $\Delta$ mutation in Saccharomyces cerevisiae highlight the importance of V-ATPase subunit balance in supporting vacuolar acidification and silencing cytosolic V1-ATPase activity. J Biol Chem. 2007;282:8521-32.

39. Simone PD, Pavlov YI, Borgstahl GE. ITPA (inosine triphosphate pyrophosphatase): from surveillance of nucleotide pools to human disease and pharmacogenetics. Mutat Res. 2013;753:131-46.

40. Smardová J, Smarda J, Koptíková J. Functional analysis of p53 tumor suppressor in yeast. Differentiation. 2005;73:261-77.

41. Gudipati V, Koch K, Lienhart WD, Macheroux P. The flavoproteome of the yeast Saccharomyces cerevisiae. Biochim Biophys Acta. 2014;1844:535-44.

42. Ledesma-Amaro R, Kerkhoven EJ, Revuelta JL, Nielsen J. Genome scale metabolic modeling of the riboflavin overproducer Ashbya gossypii. Biotechnol Bioeng. 2014;111:1191-9.

43. Mack M, van Loon APGM, Hohmann HP. Regulation of riboflavin biosynthesis in Bacillus subtilis is affected by the activity of the flavokinase/ flavin adenine dinucleotide synthase encoded by ribC. J Bacteriol. 1998;180: 950-5.

44. Henriques BJ, Olsen RK, Bross P, Gomes CM. Emerging roles for riboflavin in functional rescue of mitochondrial $\beta$-oxidation flavoenzymes. Curr Med Chem. 2010;17:3842-54.

45. Mateos L, Jiménez $A$, Revuelta JL, Santos MA. Purine biosynthesis, riboflavin production, and trophic-phase span are controlled by a Myb-related transcription factor in the fungus Ashbya gossypii. Appl Environ Microbiol. 2006;72:5052-60

46. Boiteux S, Jinks-Robertson S. DNA repair mechanisms and the bypass of DNA damage in Saccharomyces cerevisiae. Genetics. 2013;193:1025-64.
47. Mookerjee SA, Lyon HD, Sia EA. Analysis of the functional domains of the mismatch repair homologue Msh1p and its role in mitochondrial genome maintenance. Curr Genet. 2005;47:84-99.

48. Pochart $P$, Woltering $D$, Hollingsworth NM. Conserved properties between functionally distinct MutS homologs in yeast. J Biol Chem. 1997;272:30345-9.

49. Drotschmann K, Clark AB, Tran HT, Resnick MA, Gordenin DA, Kunkel TA Mutator phenotypes of yeast strains heterozygous for mutations in the MSH2 gene. Proc Natl Acad Sci U S A. 1999;96:2970-5.

50. Hodel KP, de Borja R, Henninger EE, Campbell BB, Ungerleider N, Light N, Wu T, LeCompte KG, Goksenin AY, Bunnell BA, Tabori U, Shlien A, Pursell ZF. Explosive mutation accumulation triggered by heterozygous human pol $\varepsilon$ proofreading-deficiency is driven by suppression of mismatch repair. Elife. 2018;7:e32692.

51. Ishihara S, Hirata A, Nogami S, Beauvais A, Latge JP, Ohya Y. Homologous subunits of 1,3-beta-glucan synthase are important for spore wall assembly in Saccharomyces cerevisiae. Eukaryot Cell. 2007;6:143-56.

52. Neiman AM. Sporulation in the budding yeast Saccharomyces cerevisiae. Genetics. 2011;189:737-65.

53. Wasserstrom L, Lengeler KB, Walther A, Wendland J. Molecular determinants of sporulation in Ashbya gossypii. Genetics. 2013;195:87-99.

54. Park S, Park HEH, Son HG, Lee SJV. The role of RNA helicases in aging and lifespan regulation. Transl Med Aging. 2017;1:24-31.

55. Grimminger-Marquard V, Lashuel HA. Structure and function of the molecular chaperone Hsp104 from yeast. Biopolymers. 2009;93:252-76.

56. Zhou H, Hu H, Zhang L, Li R, Ouyang H, Ming J, Jin C. OMannosyltransferase 1 in Aspergillus fumigatus (AfPmt1p) is crucial for cell wall integrity and conidium morphology, especially at an elevated temperature. Eukaryot Cell. 2007;6:2260-8.

57. Goto M, Harada Y, Oka T, Matsumoto S, Takegawa K, Furukawa K. Protein Omannosyltransferases B and C support hyphal development and differentiation in Aspergillus nidulans. Eukaryot Cell. 2009;8:1465-74.

58. Stehling $\mathrm{O}$, Lill R. The role of mitochondria in cellular iron-sulfur protein biogenesis: mechanisms, connected processes, and diseases. Cold Spring Harb Perspect Biol. 2013;5:a011312.

59. Paul BT, Manz DH, Torti FM, Torti SV. Mitochondria and Iron: current questions. Expert Rev Hematol. 2017;10:65-79.

60. Bolger AM, Lohse M, Usadel B. Trimmomatic: A flexible trimmer for Illumina Sequence Data. Bioinformatics. 2014;30:btu170.

61. Li H. Aligning sequence reads, clone sequences and assembly contigs with BWA-MEM. arXiv. 2013:1303-3997 v1 [q-bio.GN]; arXiv.org.

62. McKenna A, Hanna M, Banks E, Sivachenko A, Cibulskis K, Kernytsky A Garimella K, Altshuler D, Gabriel S, Daly M, DePristo MA. The genome analysis toolkit: a MapReduce framework for analyzing next-generation DNA sequencing data. Genome Res. 2010;20:1297-303.

63. Cingolani P, Platts A, Wang le L, Coon M, Nguyen T, Wang L, Land SJ, Lu X, Ruden DM. A program for annotating and predicting the effects of single nucleotide polymorphisms, SnpEff: SNPs in the genome of Drosophila melanogaster strain w1118; iso-2; iso-3. Fly (Austin). 2012;6:80-92.

64. El-Gebali S, Mistry J, Bateman A, Eddy SR, Luciani A, Potter SC, Qureshi M, Richardson LJ, Salazar GA, Smart A, Sonnhammer ELL, Hirsh L, Paladin L, Piovesan D, Tosatto SCE, Finn RD. The Pfam protein families database in 2019. Nucleic Acids Res. 2019;47:D427-32.

\section{Publisher's Note}

Springer Nature remains neutral with regard to jurisdictional claims in published maps and institutional affiliations.

Ready to submit your research? Choose BMC and benefit from:

- fast, convenient online submission

- thorough peer review by experienced researchers in your field

- rapid publication on acceptance

- support for research data, including large and complex data types

- gold Open Access which fosters wider collaboration and increased citations

- maximum visibility for your research: over $100 \mathrm{M}$ website views per year

At BMC, research is always in progress.

Learn more biomedcentral.com/submission 